\title{
Formal and informal abortion services in Rajasthan, India: Results of a situation analysis
}

\author{
Sandhya Barge \\ Hillary J. Bracken \\ Population Council \\ Batya Elul \\ Population Council \\ Nayan Kumar \\ Wajahat U. Khan
}

See next page for additional authors

Follow this and additional works at: https://knowledgecommons.popcouncil.org/departments_sbsr-rh

Part of the Family, Life Course, and Society Commons, International Public Health Commons, and the Maternal and Child Health Commons

How does access to this work benefit you? Let us know!

\section{Recommended Citation}

Barge, Sandhya, Hillary J. Bracken, Batya Elul, Nayan Kumar, Wajahat U. Khan, Shalini Verma, and Carol Camlin. 2004. "Formal and informal abortion services in Rajasthan, India: Results of a situation analysis." New Delhi: Population Council. 


\section{Authors}

Sandhya Barge, Hillary J. Bracken, Batya Elul, Nayan Kumar, Wajahat U. Khan, Shalini Verma, and Carol Camlin 


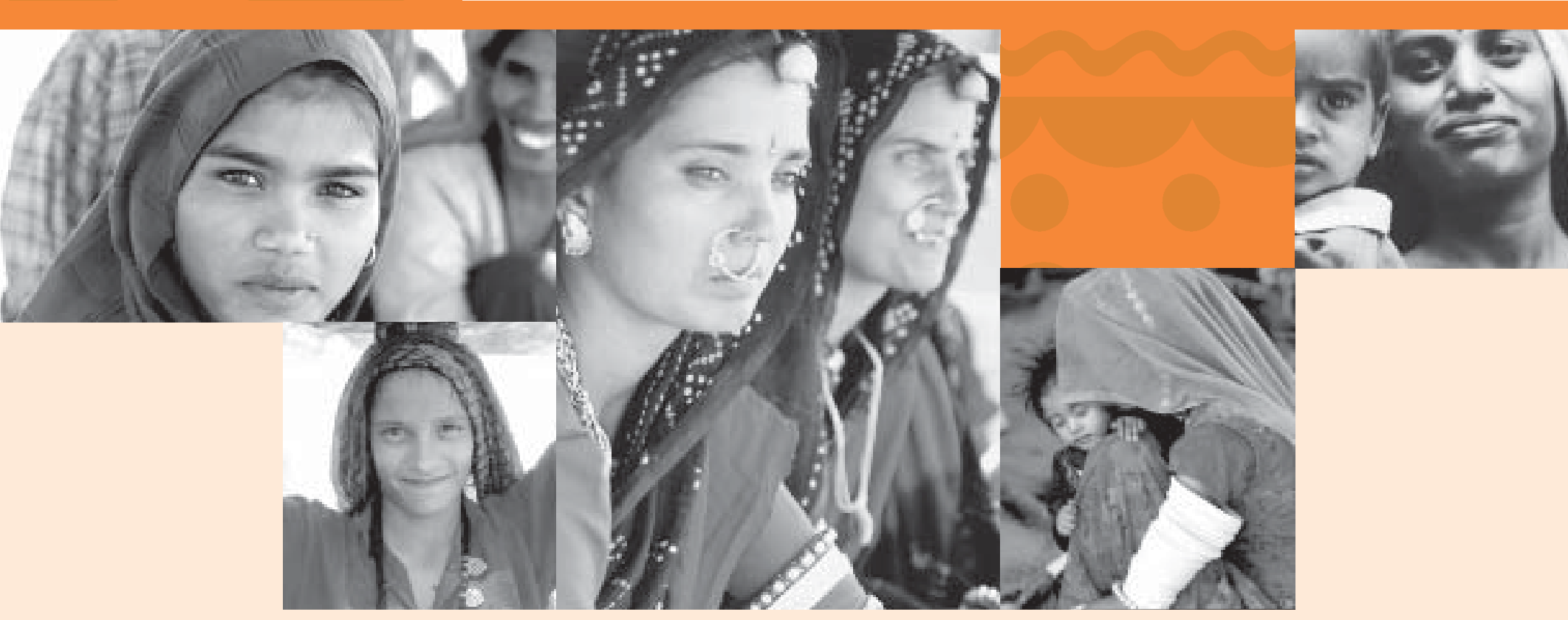

Formal and Informal Abortion Services in Rajasthan, India: Results of a Situation Analysis 
This report is the result of a collaborative project between the Population Council and the Centre for Operations Research and Training, conducted as part of a Council programme of research on unwanted pregnancy and induced abortion in Rajasthan, India. Designed as a complement to service-delivery activities being undertaken in Rajasthan by the Indian non-governmental reproductive health service provider Parivar Seva Sanstha, the programme of research aimed to provide a multi-faceted picture of the on-the-ground realities related to unwanted pregnancy and abortion in six districts of Rajasthan.

\section{For additional copies of this report, please contact:}

Ms. Vijaya Nidadavolu

Population Council

Zone 5A, Ground Floor

India Habitat Centre

Lodi Road

New Delhi 110 003, INDIA

Tel: 91-11-2464 2901/2

Fax: 91-11-2464 2903

Email: vijaya@pcindia.org

\section{Ms. Virginia Kallianes}

Population Council

1 Dag Hammarskjold Plaza

New York, NY 10017 USA

Tel: $1-212-339-0500$

Fax: 1-212-755-6052

Email: vkallianes@popcouncil.org

\section{Dr. Sandhya Barge}

Centre for Operations Research and Training 402 Woodland Apartment, Race Course Circle Vadodara 390 007, INDIA

Tel: 91-265-234 1253

Fax: 91-265-234 2941

Email: cort10@satyam.net.in

\section{For more information on Parivar Seva Sanstha's activities in Rajasthan, please contact:}

\section{Ms. Poonam Arora}

Parivar Seva Sanstha

C-374 Defence Colony

New Delhi 110 024, INDIA

Tel: $91-11-24337142 / 2524 / 7712$

Fax: 91-11-2433 6337/2585/6710

Email:parivarseva@vsnl.com
Parivar Seva Sanstha

Project Office (Rajasthan)

Flat No. A 1/1, Yamuna Path

Ganga Path, Suraj Nagar

West Civil Lines

Jaipur 302 001, INDIA

Tel: 91-141-222 1274

Fax: 91-141-222 1196

Email: parivarsevaro-jp@eth.net

The Population Council is an international, non-profit, non-governmental organisation that seeks to improve the well-being and reproductive health of current and future generations around the world and to help achieve a humane, equitable and sustainable balance between people and resources. The Council conducts biomedical, social science and public health research and helps build research capacities in developing countries.

The Centre for Operations Research and Training (CORT) is a leading multidisciplinary social science research and training organisation with headquarters in Vadodara, Gujarat. Over the last 13 years it has undertaken diagnostic, evaluation and operations research on various components of reproductive health, population, women and other social issues.

Parivar Seva Sanstha is a national non-governmental organisation providing reproductive health services with an emphasis on family planning. Registered in 1978, the organisation today has a strong network of 40 reproductive health clinics, a contraceptive products marketing and distribution system, and numerous projects and outreach activities located in 21 states of India. 


\title{
Formal and Informal Abortion Services in Rajasthan, India: Results of a Situation Analysis
}

\author{
Sandhya Barge \\ Hillary Bracken \\ Batya Elul \\ Nayan Kumar \\ Wajahat U. Khan \\ Shalini Verma \\ Carol Camlin
}





\section{Contents}

Acknowledgements $\quad \mathrm{v}$

Acronyms

Abstract $\quad$ vii

$\begin{array}{ll}\text { Chapter 1: Introduction } & 1\end{array}$

Background 1

Study objectives 2

Sampling 2

Data collection and analysis $\quad 4$

Sample coverage $\quad 6$

About this report 9

Chapter 2: The Formal Sector: Profile of Health Facilities and Personnel $\quad 10$

$\begin{array}{ll}\text { Health facilities } & 10\end{array}$

Head administrators $\quad 12$

Formal providers 13

Chapter 3: The Formal Sector: Readiness, Accessibility and Caseloads of Abortion Facilities 14

Readiness to provide services $\quad 14$

Accessibility 17

Gestational age limits and caseloads $\quad 20$

Chapter 4: The Formal Sector: Provider Training, Methods and Standard Care 23

Provider skills and training $\quad 23$

Length of stay 26

Referral patterns $\quad 26$

Pre-abortion care and counselling $\quad 27$

Post-abortion care and counselling $\quad 27$

Management of abortion complications $\quad 29$

New reproductive health technologies $\quad 31$

Familiarity with and attitudes about abortion legislation 32 
Chapter 5: The Informal Sector: Personnel and Services 34

Profile of informal abortion providers $\quad 34$

$\begin{array}{ll}\text { Training } & 34\end{array}$

Location of services and manner in which clients learn of them 35

Treatments offered to women with delayed menstruation or unwanted pregnancy 36

Counselling practices $\quad 36$

New reproductive health technologies 37

$\begin{array}{ll}\text { Familiarity with and attitudes about abortion legislation } & 38\end{array}$

Chapter 6: Summary of Findings and Conclusion 40

References

Authors 


\section{Acknowledgements}

This study and report were made possible by the hard work, dedication and input of many people. We are very grateful to the Centre for Enquiry into Health and Allied Themes in Mumbai for graciously allowing us to adapt the Abortion Assessment Project of India's abortion service situation analysis methodology and instruments for use in this study. The contributions of the 16 interviewers and supervisors who collected the data in both remote and near sites in Rajasthan were essential to the success of this study. We similarly thank all of the providers who participated in the study despite their busy schedules. We are especially indebted to Professor M.M. Gandotra and other colleagues at the Centre for Operations Research and Training in Vadodara for their guidance and support throughout the study, as well as Ms. Seema Narverkar, also from the Centre for Operations Research and Training, for valuable assistance with data cleaning and analysis. We also appreciate Ms. Vijaya Nidadavolu's assistance in the preparation of this report. Finally, we express gratitude to an anonymous donor and the John D. and Catherine T. MacArthur Foundation for providing financial support for this study. 


\section{Acronyms}

$\begin{array}{ll}\text { BAMS } & \text { Bachelor of Ayurvedic Medicine and Surgery } \\ \text { BUMS } & \text { Bachelor of Unani Medicine and Surgery } \\ \text { DHMS } & \text { Diploma of Homeopathic Medicine and Surgery } \\ \text { DGO } & \text { Diploma in Gynaecology and Obstetrics } \\ \text { DNB } & \text { Diplomate of National Board } \\ \text { MBBS } & \text { Bachelor of Medicine and Bachelor of Surgery } \\ \text { MD } & \text { Doctor of Medicine } \\ \text { MS } & \text { Masters of Science } \\ \text { MTP } & \text { Medical Termination of Pregnancy }\end{array}$




\section{Abstract}

As part of a Population Council programme of research on unwanted pregnancy and induced abortion in Rajasthan, the Population Council and the Centre for Operations Research and Training conducted a situation analysis of abortion services in both the formal and informal sectors in six districts of Rajasthan. Non-random sampling procedures were used to select formal-sector abortion facilities and informal-sector abortion providers in purposively selected district headquarters and several medium-sized towns, as well as in villages and smaller towns surrounding those urban localities. As we interviewed administrators and providers, and conducted physical and equipment assessments at both certified and uncertified abortion facilities in the formal sector, and interviewed a range of abortion providers in the informal sector, the study offers important insights into the availability and organisation of abortion services in the sampled areas in Rajasthan.

Despite a strong national commitment to improve the accessibility of abortion services in India, the study shows that only one-third (35 percent) of the 105 formal-sector facilities offering abortion in our sample are in the public sector and just 28 percent are in rural areas. Among the lower-level public facilities identified in the catchment area, only 21 percent of primary health centres and 65 percent of community health centres offer abortion services, suggesting that poor rural women have few options when faced with unwanted pregnancy.

Almost two-thirds ( 65 percent) of private-sector facilities and 58 percent of public-sector facilities sampled are not certified to provide abortions under the MTP Act. Although the majority of facilities are not certified to provide abortions, 63 percent of the 119 formal-sector abortion providers interviewed have the requisite education and/or training to perform abortions, indicating that services in the formal sector, whether legal or not, are likely to be safe. Nonetheless, the study findings also indicate that the quality of services in the formal sector can be improved substantially. The majority of formal-sector abortion providers use outdated techniques to perform surgical abortions, including dilatation and curettage. The easier and safer techniques of electric and manual vacuum aspiration are used far less frequently, even for abortions at the earliest gestational ages. Pain management for surgical procedures can be similarly improved as our study identified a substantial proportion of providers using either general anaesthesia or no pain management for first-trimester abortions.

Significant social barriers to care exist. Facilities routinely refuse to perform abortions in a number of circumstances, including if a woman presents alone, is married but nulliparous or is unmarried. Although not required by law, consent of women's husbands and other family members is not uncommon and may impede women's ability to reach their reproductive goals. While formal-sector providers are well aware of the majority of circumstances under which abortion is legal in India, confusion remains regarding the legality of abortion for unmarried women. 
The study also documented a vast array of informal providers who offer services for delayed menstruation or unwanted pregnancy. Informal providers appear particularly accessible to women because they are far more prevalent in rural areas than formal providers, are generally well known in the community in which they practise, maintain extended working hours, and sometimes provide care at women's homes. The majority of informal providers offer tablets to provoke abortions but report low success rates with them. Few informal providers report using invasive methods for the treatment of delayed menstruation.

Taken together, these findings clearly underscore the need to improve access to affordable, high-quality, legal abortion services, particularly in rural areas. Until this is done, informal providers and uncertified facilities will remain the best option for poor and rural women despite the fact that abortion has been legal in India for over 30 years. 


\section{Introduction}

\section{Background}

Following the enactment of the Medical Termination

of Pregnancy (MTP) Act in 1971, women in India have been entitled to legal abortion services for a broad range of social and economic reasons. With only three countries having more progressive abortion legislation at that time, the MTP Act was hailed globally as a landmark legislation. In addition to the medical indications permitted in many other countries including physical danger to the mother's health, rape and foetal malformations - the MTP Act permits abortion in cases of potential injury to the mother's mental health and, among married women, contraceptive failure. Abortion is permitted upto 20 weeks of gestation and no spousal consent is required, although guardian consent is required for women under 18 years of age (Government of India 1971).

In addition to specifying the circumstances under which abortion may be provided, the MTP Act and its associated Rules and Regulations stipulate both where pregnancy terminations may be offered and who may legally provide them. All allopathic public facilities at the primary health centre level and above may provide abortion services. Such public facilities need not demonstrate the availability of specific infrastructure in order to legally provide pregnancy terminations. Private facilities, however, must meet a set of minimum standards and apply for and receive certification in order to provide abortions. While the MTP Act defines the national guidelines for the approval of private facilities, some states have modified them, adding or changing the minimum qualifications for the provision of abortion services.
For example, Maharashtra state further requires private facilities seeking certification to document easy access (i.e. within five kilometres) to a blood bank (Hirve 2003).

As for certified providers of abortion services, the MTP Act specifies that only doctors practising modern allopathic medicine who are either trained in obstetrics and gynaecology or have undergone a government-sanctioned training in pregnancy termination may legally provide abortions. According to the MTP Act, practitioners of alternative systems of medicine or mid-level paramedical personnel are not permitted to provide abortions. As is the case with the certification of facilities, however, some states have modified these guidelines. Maharashtra state, for example, permits ayurvedic medical practitioners working in the public sector to perform abortions after completing a governmentsanctioned training (Hirve 2003).

While these provisions built in the MTP Act were intended to reduce the incidence of illegal abortion, they have not routinely resulted in increased access to safe abortion and abortion-related morbidity and mortality remain significant (Chhabra and Nuna 1994; Ganatra 2000; Johnston 2002). Despite an increase in the number of certified abortion facilities from 1,877 in 1976 to 9,467 in 1997, access to legal services remains poor in many parts of the country, particularly in rural areas (Khan et al 1999; Johnston 2002). With only 240 recognised abortion training centres nationwide, non-gynaecologist doctors lack adequate opportunities to be certified in abortion. 
Available data suggest that access to abortion services is particularly poor in the less-developed states of north India, including Rajasthan, where this study took place (Chhabra and Nuna 1994; Johnston 2002). Indeed, estimates indicate one legal abortion facility per 157,354 individuals in Rajasthan. Not surprisingly then, nearly all of the estimated 352,000 induced abortions that occur every year in Rajasthan are performed illegally by uncertified medical or non-medical practitioners (Chhabra and Nuna 1994).

Recognising this situation, Parivar Seva Sanstha, an Indian non-governmental reproductive health service provider, launched an initiative to prevent and respond to unwanted pregnancy in Rajasthan in early 2001. Their intervention focuses on increasing access to safe, affordable and high-quality family planning and abortion services, and conducting community outreach to inform men, women and providers about the availability of such services. As a complement to these service-delivery activities, the Population Council undertook a programme of research on unwanted pregnancy and induced abortion in Rajasthan. The Council's programme was comprised of both qualitative and quantitative studies and was intended to provide a multi-faceted picture of the on-the-ground realities related to unwanted pregnancy and abortion in Rajasthan. The situation analysis of formal and informal abortion services described in this report is among the studies conducted as part of that programme of research.

\section{Study objectives}

Researchers from the Population Council and the Centre for Operations Research and Training built on the methodology developed by the Abortion Assessment Project of India to assess the existence, management, organisation and quality of abortion services in both the formal (public and private) and informal sectors in six districts of Rajasthan (Duggal and Barge 2003). ${ }^{1}$ As we had collected significant qualitative and quantitative data on abortion from women and men at the community level in those districts (Elul et al 2004a; Elul et al 2004 b), this study was designed to fill in gaps related to the supply of abortion services in the same areas.

\section{Sampling}

The situation analysis was conducted in six districts of Rajasthan - Alwar, Bhilwara, Bikaner, Karauli, Pali and Tonk - where the Population Council and the Centre for Operations Research and Training conducted a community-based survey of unwanted pregnancy and abortion among married women and men in late 2001 (Elul et al 2004a). ${ }^{2}$ A few key indicators of the sampled districts are displayed in Table 1.1.

As the situation analysis was designed to complement the 2001 community-based survey, the catchment area was matched to that used in the earlier study. The catchment area for the situation analysis thus included district headquarters and all towns and villages falling within a 35-kilometre radius of the district headquarters, as well as six

\footnotetext{
${ }^{1}$ The six districts in this study do not overlap with those sampled in the Rajasthan portion of the multicentre study conducted by the Abortion Assessment Project of India.

${ }^{2}$ For details on the rationale for selecting these six districts, please see Elul et al (2004).
} 
pre-specified towns and all villages falling within a 10-kilometre radius of those towns. ${ }^{3}$

Within those catchment areas, we sampled facilities providing abortion services in the formal sector, as well as providers offering such services in the informal sector:

- Formal-sector facilities were defined as those staffed by providers with training (whether allopathic or in Indian systems of medicine) from institutions that award degrees or diplomas (i.e. MD, MBBS, BAMS, BUMS, DHMS). The facility did not need to be certified to provide abortions under the MTP Act to be included in our study.

Facilities were sampled from both the public and private sectors. In the public sector, all government facilities at the primary health centre and above falling in our catchment area were included on the original sampling list. In the private sector, all facilities certified by the Government of India to

Table 1.1

Summary socio-demographic and health statistics for sampled districts and for the state of Rajasthan

\begin{tabular}{|c|c|c|c|c|c|c|c|}
\hline District & Alwar & Bhilwara & Bikaner & Karauli & Pali & Tonk & Rajasthan \\
\hline Population & $2,990,862$ & $2,009,516$ & $1,673,562$ & $1,205,631$ & $1,819,201$ & $1,211,343$ & $56,473,122$ \\
\hline Density & 357 & 192 & 61 & 218 & 147 & 168 & 165 \\
\hline \multicolumn{8}{|l|}{ Literacy rate (\%) } \\
\hline Overall & 62.5 & 51.1 & 57.5 & 64.6 & 54.9 & 52.4 & 61.0 \\
\hline Female & 44.0 & 33.5 & 42.6 & 45.4 & 36.7 & 32.3 & 44.3 \\
\hline Child sex ratio & 888 & 951 & 915 & 876 & 927 & 922 & 909 \\
\hline Contraceptive use (\%) & 40.4 & 32.9 & 40.6 & 25.6 & 34.2 & 36.0 & 33.2 \\
\hline Institutional deliveries (\%) & 15.9 & 17.9 & 25.0 & 26.5 & 14.5 & 13.4 & 19.8 \\
\hline \multicolumn{8}{|l|}{ Density: Population per square kilometre. } \\
\hline \multicolumn{8}{|l|}{ Sex ratio: Number of girls to boys' aged 0-6. } \\
\hline Population, density, literacy rate, and sex & atio: Census of In & 2002. & & & & & \\
\hline
\end{tabular}

\footnotetext{
${ }^{3}$ While the catchment area for the community-based survey was restricted to a 25-kilometre radius of the district headquarters and a five-kilometre radius of the pre-specified towns, the catchment area was expanded slightly in this study. This was done to capture services that may be used by women who reside on the outer edge of the catchment area from the community-based study. For example, a woman who lives 23 kilometres from a district headquarter may seek services in a town 30 kilometres from the district headquarters rather than from the district headquarter itself.
} 
provide abortions were also included on the sampling list. Additionally, as many private facilities that offer abortion are not certified under the MTP Act, other private facilities were identified and added to the sampling list using snowball techniques based on input from key informants (i.e. district health officers, chemists, hospitals, drug wholesalers). The study team also conducted a thorough canvassing of the main commercial areas of towns and large villages located in the catchment area to identify additional uncertified private facilities.

For each formal-sector facility included on the original sampling list, we documented whether abortion services were actually being provided at the facility and whether the facility administration was willing to participate in the study. The final sample of formal-sector facilities was comprised of those that were providing abortion services at the time of data collection and had consented to participate in the study.

Informal providers included all paramedical personnel, such as auxiliary nurse midwives, community health workers, compounders, chemists, dais, lady health workers, male health workers, nurses and rural medical practitioners. The sample for the informal sector was developed using the same approach taken for the private, formal sector. Potential respondents were identified in the same catchment area using inputs from key informants (i.e. personnel from primary health centres, community health centres and hospitals, chemists, community leaders in villages) and a thorough canvassing of the main commercial areas of towns and villages in the catchment area.

All informal providers who reported providing services to women for delayed menstruation or unwanted pregnancy at the time of data collection and were willing to participate in the study were interviewed.

\section{Data collection and analysis}

All data collection occurred between July and October 2002. Four structured instruments were used.

Three were used to collect information in the formal sector - a head administer questionnaire, a provider questionnaire, and a facility observation checklist and one to gather data in the informal sector a provider questionnaire (Table 1.2). The study interviewers completed each of the instruments. We did not interview any clients or directly observe any provider interactions with clients.

In the formal sector, the first of the three instruments was used to interview the head of each sampled facility. (In some cases the facility head was not a provider, while in other cases the facility head was the sole provider. In the case of district hospitals, the head of the obstetrics and gynaecology ward was interviewed rather than the head of the hospital).

The instrument included questions about the management of the facility, the services provided, the number and training of all abortion providers working at the facility, and the facility's MTP certification status. If the facility was providing abortion services but was not certified to do so under the MTP Act, information was collected on impediments to certification. The second instrument used in the formal sector, a provider questionnaire, was addressed to all abortion providers at each sampled facility. (In some cases, an abortion 


\section{Table 1.2}

Data collection instruments, respondents and topic areas

\begin{tabular}{|c|c|c|c|}
\hline Health sector & Instrument & Respondent/observer & Main topics \\
\hline Formal & $\begin{array}{l}\text { Head administrator } \\
\text { questionnaire }\end{array}$ & Facility supervisor & $\begin{array}{l}\text { Facility characteristics } \\
\text { Staffing profile } \\
\text { Services offered } \\
\text { Caseload } \\
\text { Operating logistics } \\
\text { Financial support }\end{array}$ \\
\hline Formal & $\begin{array}{l}\text { Formal provider } \\
\text { questionnaire }\end{array}$ & $\begin{array}{l}\text { BAMS, BUMS, DHMS, DGO, } \\
\text { DNB, MBBS, MD, MS }\end{array}$ & $\begin{array}{l}\text { Professional qualifications/training } \\
\text { Caseload } \\
\text { Treatment protocols } \\
\text { Pain management strategies } \\
\text { Recovery and referral protocols } \\
\text { Counselling content } \\
\text { Knowledge of medical abortion } \\
\text { and emergency contraception } \\
\text { Knowledge of abortion legislation } \\
\text { Attitudes regarding abortion }\end{array}$ \\
\hline Formal & Observation checklist & Observation/interview & $\begin{array}{l}\text { Physical infrastructure } \\
\text { Basic furniture and tools } \\
\text { Gynaecology equipment } \\
\text { Essential drugs } \\
\text { Emergency equipment } \\
\text { Infection prevention supplies } \\
\text { Waste disposal practices } \\
\text { Contraceptive methods available } \\
\text { Education and counselling } \\
\text { materials available }\end{array}$ \\
\hline Informal & Provider questionnaire & $\begin{array}{l}\text { Auxiliary nurse midwife, chemist, } \\
\text { community health worker, } \\
\text { compounder, dai, lady health } \\
\text { visitor, male health worker, nurse, } \\
\text { rural medical practitioner, } \\
\text { village practitioner }\end{array}$ & $\begin{array}{l}\text { Professional qualifications/training } \\
\text { Caseload } \\
\text { Services offered } \\
\text { Treatment protocols } \\
\text { Pain management strategies } \\
\text { Recovery and referral protocols } \\
\text { Counselling content } \\
\text { Knowledge of medical abortion } \\
\text { and emergency contraception } \\
\text { Knowledge of abortion legislation } \\
\text { Attitudes regarding abortion }\end{array}$ \\
\hline
\end{tabular}


provider was also the facility head). This instrument documented providers' training, as well as the abortion and post-abortion procedures and treatments they used, and their knowledge and attitudes regarding abortion-related legislation. Finally, for each facility, an observation checklist was used to document the facility infrastructure and equipment.

In the informal sector, the provider questionnaire documented respondents' training, skills, competence, as well as the technologies and techniques they used for abortion, and their knowledge and attitudes regarding abortion-related legislation.

Questionnaires were drafted in English and translated into Hindi. As similar instruments had been widely used in India, including Rajasthan, the pretest was very small in scale. Each instrument was tested approximately four times and modified accordingly.

Thirteen data collectors and three supervisors were recruited from the study area for data collection and trained by staff from the Centre for Operations Research and Training and the Population Council, as well as medical doctors. Interviews were conducted in English and Hindi. Participation in this study was voluntary and uncompensated. All respondents gave oral informed consent before being interviewed. The data were entered and cleaned using Fox Pro and transferred to STATA 8.0 for analysis.

As the study districts, facilities and respondents were not randomly selected, the results are not generalisable to the study area or districts, the state of Rajasthan or other parts of India. Additionally, as the final sample size is small, care should be taken when interpreting the results presented in this report.

\section{Sample coverage}

Figure 1.1 shows the response rates for the sample in the formal sector. The study team identified 659 facilities in the private and public sectors that were believed to provide abortion services using government lists of certified providers and snowball techniques. Among those facilities, only 209 actually reported providing abortion services at the time of the study. Two hundred of those 209 facilities agreed to participate in the study. Head administer questionnaires, provider questionnaires and observation checklists were all completed at 116 of those 200 facilities. Of the 116 facilities where all three instruments were completed, four facilities were subsequently excluded from the analysis as they were found to have provided abortion services in the past but were not doing so at the time of the study. An additional seven facilities with missing data on the cost and availability of abortion services were also excluded from the analysis. The final formal-sector sample used in this report consists of 105 facilities 70 providing surgical abortion services and 35 providing non-invasive abortion services - and the 119 abortion providers interviewed at those facilities.

In the informal sector, snowball sampling techniques identified 2,212 informal providers who were believed to provide services to women with delayed menstruation or unwanted pregnancy (Figure 1.2). Further investigation indicated that 1,600 of those informal providers were actually offering services to such women. When asked to participate in the study, 497 of those 1,600 informal providers agreed to participate. Of the 497 respondents interviewed, 489 were included in the final analysis. Seven informal providers were excluded from the 


\section{Figure 1.1}

Formal-sector sample coverage

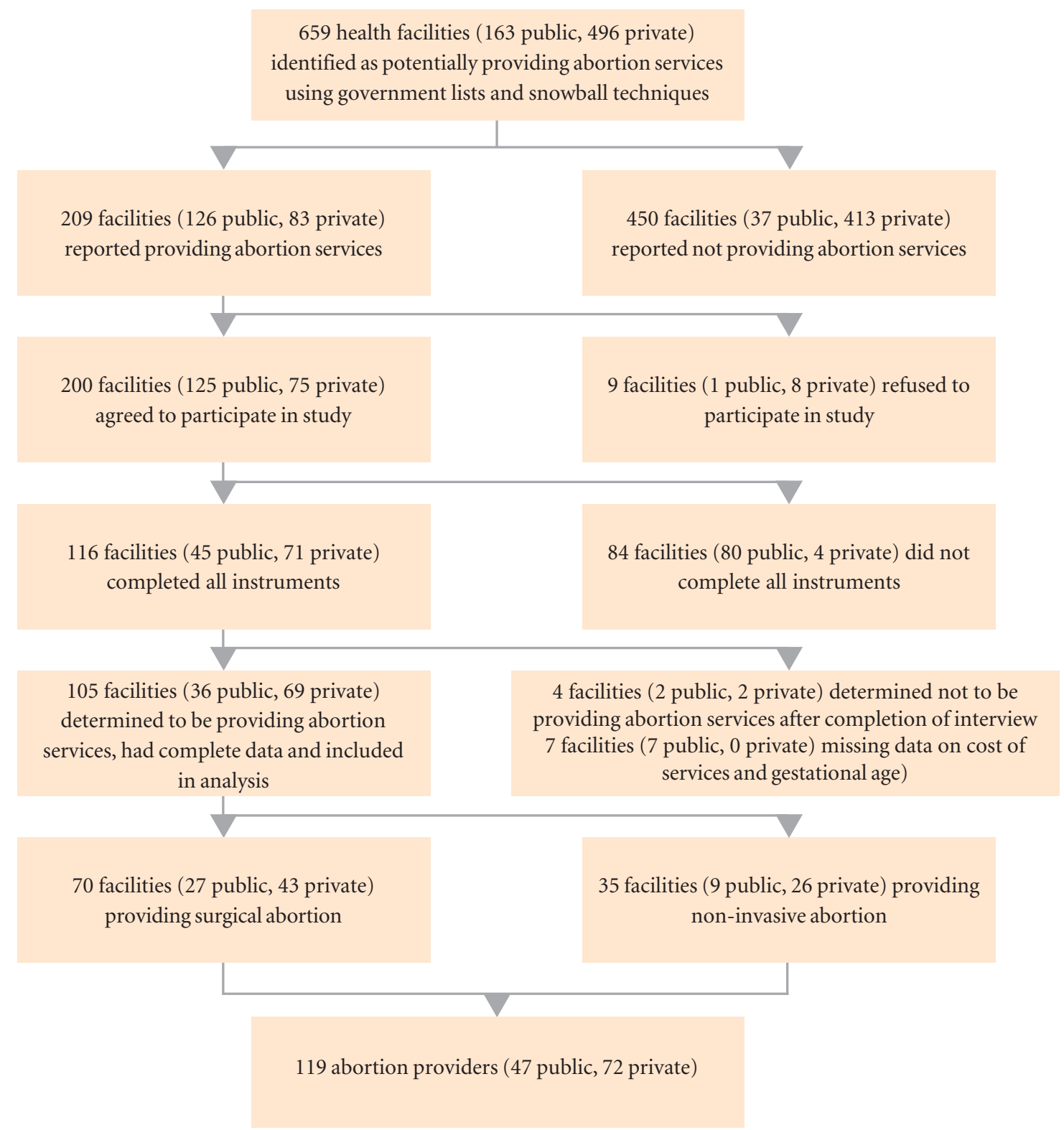


Figure 1.2

Informal-sector sample coverage

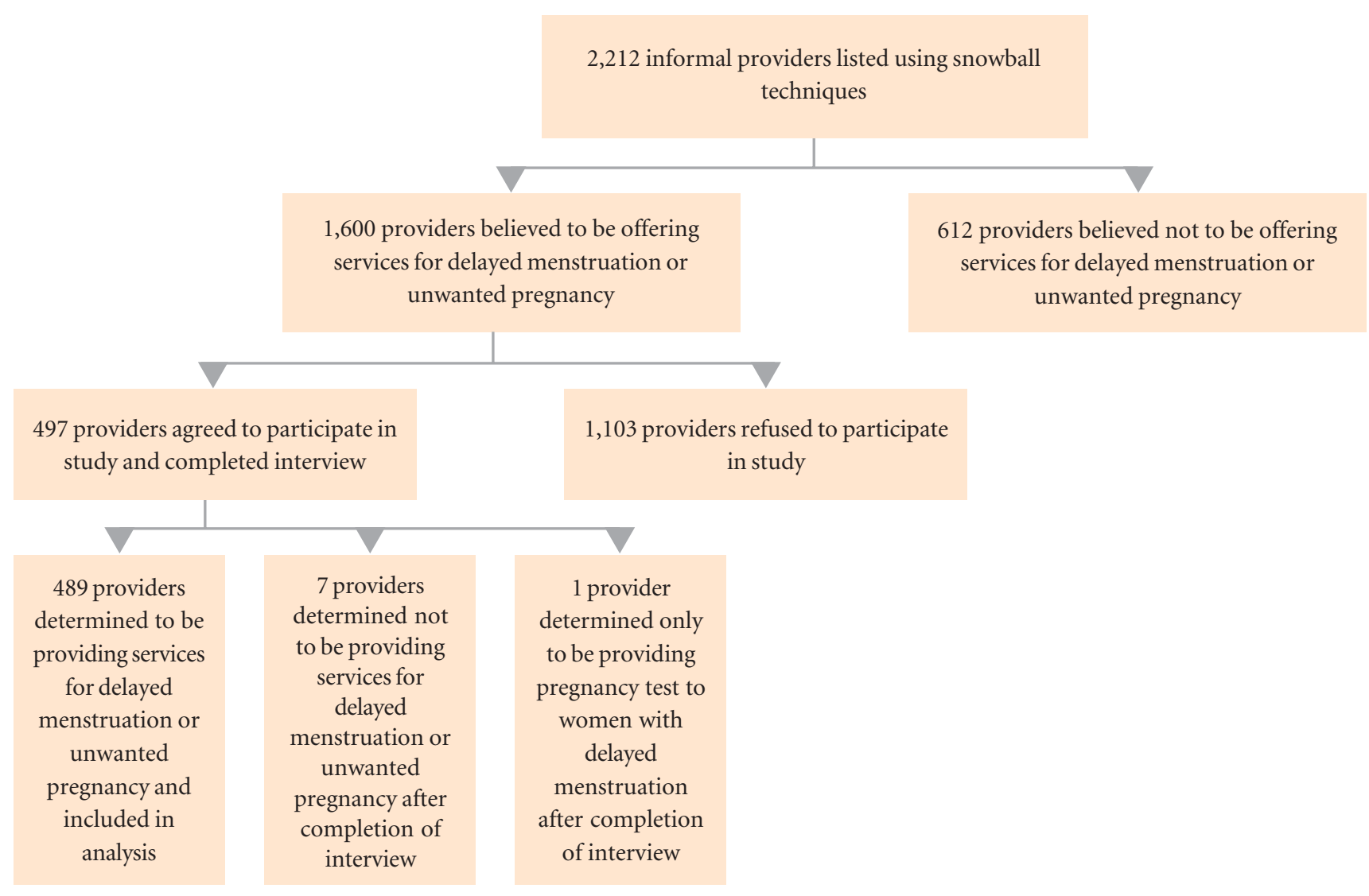


analysis because it was determined that they were not actually providing services for delayed menstruation or unwanted pregnancy. One additional provider was excluded because he reported only providing pregnancy tests to women with delayed menstruation.

\section{About this report}

This report has five main sections:

- Chapter 2 describes the profile of the health facilities, head administrators and providers sampled in the formal sector;

- Chapter 3 examines the ability of health facilities in the formal sector to provide abortion services and their caseloads. The analysis is disaggregated by whether the facility was located in the public or private sector;

- Chapter 4 explores the ability of providers to provide high-quality services by examining their technical competence and screening, treatment, follow-up and counselling procedures. These data are disaggregated by whether the provider was practising in the public or private sector. These classifications are based on the type of facility in which the provider was interviewed and do not reflect the fact that doctors may work in both the public and private sectors: For example, a gynaecologist with a position in a government hospital may also maintain a private practice outside of working hours. We did not explicitly ask providers in the public sector whether they maintained a separate private practice or ask private providers whether they also held a position in a public facility. Data regarding abortion techniques are also disaggregated by whether a provider was certified to legally provide abortion services. Providers who reported that they had the necessary education or training were considered to be certified. Those providers who reported that they did not have the requisite education or training were considered uncertified to provide legal abortion services. Interviewers did not verify the providers' certification status;

- Chapter 5 describes the profile and training of the informal abortion providers sampled. In an effort to explore the scope and quality of their services, the section also examines the treatment, counselling and follow-up procedures used by informal providers; and

- Chapter 6 summarises the findings of this study and offers policy and programmatic recommendations to ensure greater access to safe abortion services in Rajasthan. 


\section{The Formal Sector: Profile of Health Facilities and Personnel}

This section describes the 105 formal-sector health facilities sampled and the 119 abortion service providers interviewed at those facilities.

\section{Health facilities}

Almost two-thirds (65 percent) of the 105 abortion facilities sampled are located in the private sector (Figure 2.1). The public-sector facilities in our sample that provide abortion services include district and tertiary hospitals ( 6 percent), community health centres (10 percent), primary health centres (10 percent), as well as ayurvedic district hospitals, and homeopathic and unani dispensaries (9 percent).

\begin{abstract}
Among all the lower-level public facilities in the catchment area (sampled and not sampled), only 21 percent of primary health centres and 65 percent of community health centres are providing abortion services (data not shown). Head administrators at the public facilities not providing abortion services report that this is because they believe the facility is uncertified under the MTP Act or because they lack the required infrastructure or personnel.

Table 2.1 describes the profile of the 105 health facilities sampled. The health facilities in our sample are unevenly distributed across the six study districts, with the majority ( 34 percent)
\end{abstract}

\section{Figure 2.1}

Distribution of types of abortion facilities

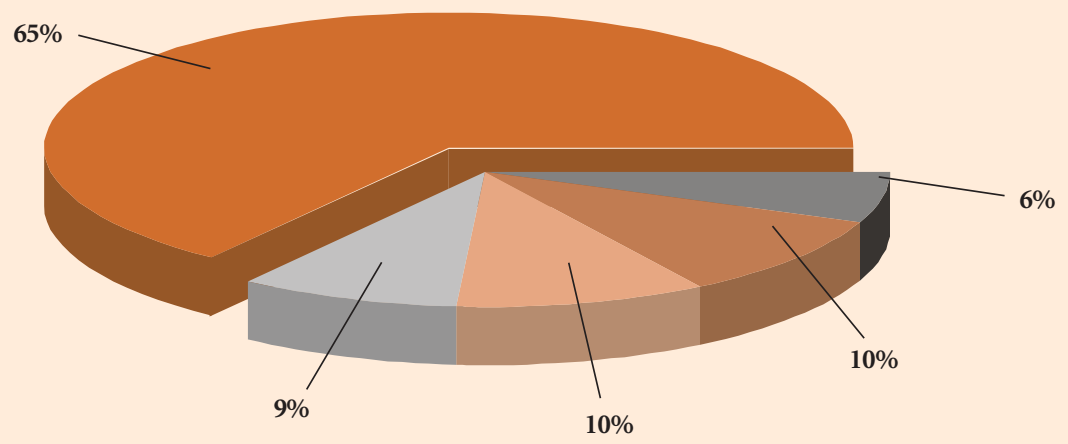

Private hospital/clinic/nursing home

Ayurvedic, unani and homeopathic facilities

Primary health centre

Community health centres

District/tertiary hospital 


\section{Table 2.1}

\section{Profile of health facilities by health sector (\%)}

\begin{tabular}{|l|c|c|c|}
\hline & Public & Private & \\
\hline Distribution of facilities district wise & & & \\
\hline Alwar & 22.2 & 40.6 & 34.3 \\
\hline Bhilwara & 19.4 & 13.1 & 15.2 \\
\hline Bikaner & 16.7 & 20.3 & 19.0 \\
\hline Karauli & 11.1 & 16.0 & 14.3 \\
\hline Pali & 13.9 & 5.8 & 8.6 \\
\hline Tonk & 16.7 & 4.4 & 8.6 \\
\hline Area & & & 72.4 \\
\hline Urban & 52.8 & 82.6 & 27.6 \\
\hline Rural & 47.2 & 17.4 & \\
\hline MTP certification status & & & 37.1 \\
\hline Certified & 41.7 & 34.8 & 62.9 \\
\hline Uncertified & 58.3 & 65.2 & $\mathbf{1 0 5}$ \\
\hline Facilities (n) & 36 & $\mathbf{6 9}$ & \\
\hline
\end{tabular}

coming from Alwar. Far fewer formal-sector, and in particular private- sector, facilities providing abortion services were sampled in the districts of Pali and Tonk. Nearly three-quarters (72 percent) of all the facilities and 83 percent of the privatesector facilities in our sample are located in urban areas. Only a little more than one-third

(37 percent) of the facilities sampled are certified to provide abortion services under the MTP Act.

Fewer private-sector facilities (35 percent) than public-sector ones (42 percent) are certified. Included among the public-sector uncertified facilities are the state ayurvedic hospital, several ayurvedic district hospitals, and homeopathic and unani dispensaries.

We gathered data on attempts and barriers to certification from the 45 uncertified private facilities offering abortion services. ${ }^{4}$ Only one-quarter (24 percent) of such facilities had attempted (unsuccessfully) to obtain MTP certification, while the majority (76 percent) had never tried to certify their facility (data not shown). Of the 34 facilities which never attempted to obtain certification, over one-fifth (21 percent) reported they did not seek certification because they provide only non-allopathic services and thus are not eligible to be certified according to the

\footnotetext{
${ }^{4}$ As the public-sector, uncertified facilities in our sample only offered non-allopathic services, they were not asked about attempts to obtain certification since according to the MTP Act such facilities cannot be certified to provide abortion services.
} 
MTP Act. Other reasons given for not attempting certification to provide abortions are a small abortion caseload, a lack of required equipment in the facility, a cumbersome and costly application process and a state-centralised certification review process (data not shown). ${ }^{5}$

Certified facilities are required to report all abortions performed in their facilities to district authorities. Most (90 percent) of the 39 certified facilities in our sample are reporting the required information and do so on a monthly basis (72 percent). Head administrators in the certified facilities which do not report abortions were further probed about the reasons for this practice.
Nearly one-fifth (18 percent) of such facilities do not report abortions because they provide only non-invasive procedures and believe that those procedures need not be reported. A few others (7 percent) do not report abortions because their caseloads are small (data not shown).

\section{Head administrators}

Table 2.2 describes characteristics of the head administrators interviewed. In both private and public facilities, most head administrators are male with a mean age of 45 years. About one-quarter have advanced training (DGO, MD or MS) in gynaecology (26 percent) or have an MBBS degree (22 percent).

Table 2.2

Profille of head administrators interviewed

\begin{tabular}{|l|r|r|r|}
\hline & Public & Private & Total \\
\hline Age (mean years) & 45.3 & 45.0 & 45.1 \\
\hline Sex (\%) & & & \\
\hline Male & 80.6 & 65.2 & 70.5 \\
\hline Female & 19.4 & 34.8 & 29.5 \\
\hline Professional qualification (\%) & & & \\
\hline MBBS & 36.1 & 14.5 & 21.9 \\
\hline DGO & - & 4.4 & 2.9 \\
\hline MD/MS in obstetrics-gynaecology & 13.9 & 27.5 & 22.9 \\
\hline MD/MS in other branch of medicine & 19.4 & 10.1 & 13.3 \\
\hline BAMS/BUMS/DHMS & 25.0 & 37.7 & 33.3 \\
\hline Other & 5.6 & 5.8 & 5.7 \\
\hline Head administrators (n) & 36 & $\mathbf{6 9}$ & $\mathbf{1 0 5}$ \\
\hline
\end{tabular}

${ }^{5}$ Around the time of our study, the MTP Act was amended to decentralise the co-ordination of facility certification from the state to the district level (Government of India 2002), thus addressing the last impediment to certification noted by our respondents. 
One-third ( 33 percent) hold a degree in an Indian system of medicine (BAMS, BUMS or DHMS).

\section{Formal providers}

Table 2.3 describes the 119 abortion providers interviewed in the 105 formal-sector health facilities included in our sample. Providers average 44 years of age. While over half ( 53 percent) of all providers are women, female providers are unevenly distributed in the private and public sector: More than half (57 percent) of providers in the private sector are female compared to less than half (47 percent) in the public sector. Over 46 percent of all providers have advanced training (DGO, MD or MS) in gynaecology. Ayurvedic, unani and homeopathic practitioners make up a greater proportion of providers in the private sector (35 percent) compared to the public sector (19 percent). Providers in the private sector have slightly more experience providing abortion services (mean 6.9 years) than providers in the public sector (mean 5.2 years).

Table 2.3

Profile of formal providers interviewed

\begin{tabular}{|l|r|r|r|}
\hline & Public & Private & Total \\
\hline Age (mean years) & 43.3 & 45.2 & 44.4 \\
\hline Sex (\%) & & & \\
\hline Male & 53.2 & 43.1 & 47.1 \\
\hline Female & 46.8 & 56.9 & 52.9 \\
\hline Professional qualification (\%) & & & \\
\hline MBBS & 31.9 & 13.9 & 21.0 \\
\hline DGO & 4.3 & 4.2 & 4.2 \\
\hline MD/MS in obstetrics-gynaecology & 36.2 & 45.8 & 4.2 \\
\hline MD/MS in other branch of medicine & 8.5 & 1.4 & 28.6 \\
\hline BAMS/BUMS/DHMS & 19.1 & 34.7 & 6.2 \\
\hline Experience providing abortion (mean years) & 5.2 & 6.9 & $\mathbf{1 1 9}$ \\
\hline Formal providers (n) & 47 & 72 & \\
\hline
\end{tabular}




\section{The Formal Sector: Readiness, Accessibility and Caseloads of Abortion Facilities}

One objective of this study was to describe the readiness and accessibility of abortion services offered in health facilities in the public and private sectors. This section presents data on various elements of preparedness, such as facility infrastructure, available equipment and personnel, and describes potential physical, financial and social barriers to services. In this chapter, we also present data on abortion caseloads.

\section{Readiness to provide services}

\section{Facility infrastructure and equipment}

Most of the 105 facilities sampled have a waiting room with a seating area ( 83 percent) or a sheltered or covered waiting area ( 82 percent). In both the public and private sectors, almost 70 percent of clinics maintain auditory privacy and almost three-quarters provide (73 percent) clients with visual privacy (data not shown).
Among the 70 facilities offering surgical services, we found substantial differences in the condition of the procedure room or operating theatre by health sector (Table 3.1). Over 90 percent of private facilities have a procedure room that is clean and dust free compared with only 56 percent of public facilities. Slightly more private clinics ( 93 percent) also have electrical connections in working order and adequate light in the procedure room than public clinics (85 percent).

Table 3.2 shows the essential equipment available at the 70 facilities providing surgical abortion services. Most clinics ( 80 percent) have an electrically operated suction machine and 50 percent have a manually operated suction machine. Private clinics, however, are slightly better equipped than public facilities. Almost three-quarters ( 74 percent) of private clinics have manual vacuum aspiration syringes compared to only 26 percent of public facilities.

\section{Table 3.1}

Condition of procedure room by health sector (\%) a

\begin{tabular}{|l|c|c|c|}
\hline & Public & Private & Total \\
\hline Procedure room clean and dust free & 55.6 & 90.7 & 77.1 \\
\hline Operation table clean and in working condition & 55.6 & 86.0 & 74.3 \\
\hline Electric connections in working condition & 85.2 & 93.0 & 90.0 \\
\hline Adequate light in procedure room & 85.2 & 93.0 & 90.0 \\
\hline Facilities providing surgical abortion (n) & $\mathbf{2 7}$ & $\mathbf{4 3}$ & $\mathbf{7 0}$ \\
\hline
\end{tabular}

${ }^{a}$ May total to more than 100 percent because of multiple responses. 
Similarly, 81 percent of private facilities have at least three sizes of suction cannulas compared to only 41 percent of public facilities.

Infection prevention equipment is adequate in most facilities. Ninety percent of clinics have an autoclave and 91 percent have a steam steriliser/boiler (Table 3.2). Seventy percent of clinics have Savlon solution, povidone iodine solution, glutaraldehyde (Cidex) solution, bleaching powder and long rubber gloves (data not shown).

Table 3.2

Equipment available by health sector (\%)

\begin{tabular}{|c|c|c|c|}
\hline & Public & Private & Total \\
\hline \multicolumn{4}{|l|}{ Essential equipment ${ }^{\text {a }}$} \\
\hline Suction machine, electrically operated & 77.8 & 81.4 & 80.0 \\
\hline Suction machine, manually operated & 40.7 & 55.9 & 50.0 \\
\hline Manual vacuum aspiration syringes & 25.9 & 74.4 & 55.7 \\
\hline Adaptors for manual vacuum aspiration syringes & 29.6 & 76.7 & 58.6 \\
\hline Forceps for holding sponges & 100.0 & 93.0 & 95.7 \\
\hline Sims' or Cusco’s speculum & 100.0 & 90.9 & 94.3 \\
\hline Tenaculum/vulsellum & 96.3 & 93.0 & 94.3 \\
\hline Anterior/posterior vaginal wall retractor & 92.6 & 93.0 & 92.9 \\
\hline Ovum forceps & 100.0 & 93.0 & 95.7 \\
\hline Sharp/blunt uterine curette & 100.0 & 93.0 & 95.7 \\
\hline Dilator set (at least 12 sizes) & 92.6 & 90.9 & 91.4 \\
\hline Suction cannulas (at least three sizes) & 40.7 & 81.4 & 65.7 \\
\hline \multicolumn{4}{|l|}{ Supporting equipment a } \\
\hline Backsight lamp/angle poise lamp & 66.7 & 90.7 & 81.4 \\
\hline Oxygen cylinder with gas & 96.3 & 90.7 & 92.9 \\
\hline Boyle’s apparatus & 74.1 & 88.4 & 82.9 \\
\hline Laryngoscope & 55.5 & 88.4 & 75.7 \\
\hline Autoclave & 88.9 & 90.7 & 90.0 \\
\hline Autoclave drum & 85.2 & 90.7 & 88.6 \\
\hline Steam steriliser/boiler & 92.6 & 90.7 & 91.4 \\
\hline Formalin chamber & 70.4 & 86.0 & 80.0 \\
\hline Facilities providing surgical abortion (n) & 27 & 43 & 70 \\
\hline
\end{tabular}

${ }^{a}$ May total to more than 100 percent because of multiple responses. 
Table 3.3

Essential drugs/supplies available by health sector (\%) a

\begin{tabular}{|l|c|c|c|}
\hline & Public & Private & Total \\
\hline Ethacridine lactate & 18.5 & 53.5 & 40.0 \\
\hline Oxytocin injection & 81.4 & 90.7 & 87.1 \\
\hline Prostaglandin injection & 18.5 & 88.4 & 61.4 \\
\hline Prostaglandin vaginal pessaries or gel & 18.5 & 72.1 & 51.4 \\
\hline Intravenous fluids & 81.5 & 86.0 & 84.3 \\
\hline Blood & 33.3 & 48.8 & 42.9 \\
\hline Analgesics & 96.3 & 88.4 & 91.4 \\
\hline Facilities providing surgical abortion (n) & $\mathbf{2 7}$ & $\mathbf{4 3}$ & $\mathbf{7 0}$ \\
\hline
\end{tabular}

${ }^{a}$ May total to more than 100 percent because of multiple responses.

In the 70 facilities providing surgical services, an attempt was made to assess the availability of drugs and supplies used for cervical priming or for instillation abortion (Table 3.3). Most public facilities (81 percent) have oxytocin injection but far fewer have prostaglandin injection (19 percent) or gel (19 percent), or ethacridine lactate (19 percent). Facilities in the private sector are far better supplied with utertonics such as oxytocin (91 percent) and prostaglandin injection (88 percent) or gel (72 percent), as well as instillation abortion products such as ethacridine lactate (54 percent). Only onethird (33 percent) of the public facilities and a little less than half ( 49 percent) of the private facilities have a blood stock onsite. Intravenous fluids and analgesics are available in more than 80 percent of the facilities in both the sectors.

\section{Availability of contraceptive methods}

While several modern contraceptive methods condoms, oral pills and intrauterine devices - are widely available in the 105 facilities we sampled, more public facilities stock these methods than those in private sector facilities (Figure 3.1). Injectable contraceptives are far less common across both health sectors, available in just over half (54 percent) of private facilities and less than one-fifth (18 percent) of public facilities.

\section{Available human resources}

Table 3.4 describes the staffing patterns in the 105 facilities surveyed. Just over half (51 percent) of all facilities have a female doctor on staff, with more private facilities ( 57 percent) compared to public facilities (39 percent) reporting female staff doctors. Facilities in the private sector are also more likely to have at least one full-time gynaecologist or social worker in the facility. At least one nurse is available in almost three quarters (74 percent) of facilities. Public-sector facilities, however, are more likely to have a nurse on staff ( 89 percent) than private-sector facilities (67 percent). 


\section{Figure 3.1}

Contraceptive methods stocked by health sector

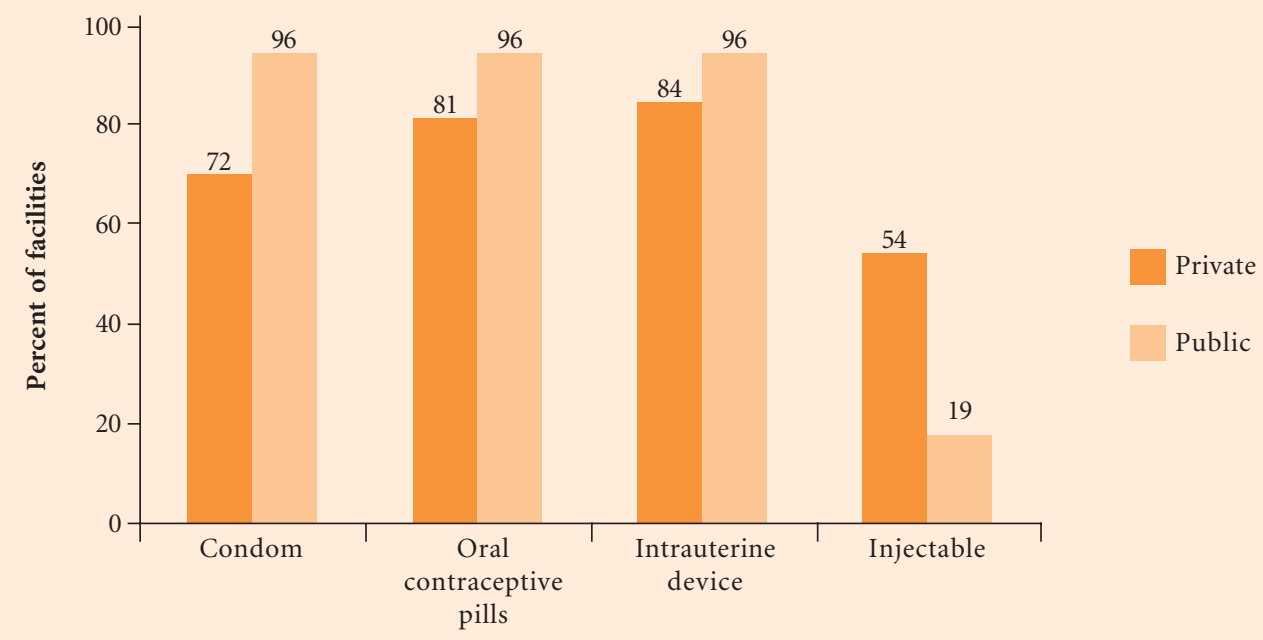

Table 3.4

Staffing patterns by health sector (\%)a

\begin{tabular}{|l|c|c|c|}
\hline & Public & Private & Total \\
\hline Female doctor & 38.9 & 56.5 & 50.5 \\
\hline At least one full-time gynaecologist & 38.9 & 46.4 & 43.8 \\
\hline At least one anaesthetist & 25.0 & 17.8 & 40.0 \\
\hline At least one social worker & - & 5.8 & 3.8 \\
\hline At least one nurse & 88.9 & 66.7 & 74.3 \\
\hline Facilities $(\mathbf{n})$ & $\mathbf{3 6}$ & $\mathbf{6 9}$ & $\mathbf{1 0 5}$ \\
\hline
\end{tabular}

${ }^{a}$ May total to more than 100 percent because of multiple responses.

\section{Accessibility}

Even if a facility has the required infrastructure and personnel to provide abortion services, these services may not be accessible to clients. This section reviews potential physical, financial and social barriers to access in the facilities surveyed.

\section{Physical accessibility}

Except for one uncertified government facility, all health facilities are accessible by road. In most cases, this road is metalled and some form of transportation is readily available - most often rickshaw (75 percent) or bus (72 percent). Private facilities are 
more likely to have a telephone ( 74 percent) than public facilities (47 percent). Only slightly more than one-third (35 percent) of facilities have a signboard/ poster in the clinic or hospital announcing that MTP services are available. Less than half ( 44 percent) of all certified facilities display the MTP certification certificate within the centre (data not shown).

\section{Cost}

Abortion services are reportedly free of cost at all gestational ages in the 15 certified public-sector facilities and three of the uncertified public-sector facilities in our sample. Table 3.5 shows the cost of abortion in Indian Rupees by gestational age at the remaining 18 uncertified public-sector clinics and the 69 certified and uncertified private-sector facilities. For private clinics and uncertified public clinics, the cost of abortion increases with gestational age. In the first trimester, the cost is greatest at certified private facilities, reaching a mean maximum of 594 Indian Rupees for abortions $\leq 8$ weeks' gestation and 671 Indian Rupees for those between 9 and 12 weeks' gestation. Among the handful of facilities that offer services in the second trimester, however, uncertified private-sector facilities charge the most, with a mean maximum cost of 2000 Indian Rupees. In nearly one-quarter (24 percent) of facilities the reported charge does not include any additional expenses such as drugs, medicines and lab tests.

Table 3.5

Cost of abortion services by health sector and certification status ${ }^{\text {a }}$

\begin{tabular}{|c|c|c|c|c|}
\hline & \multirow{2}{*}{$\begin{array}{c}\text { Public } \\
\text { Uncertified }\end{array}$} & \multicolumn{2}{|c|}{ Private } & \multirow[t]{2}{*}{ Total } \\
\hline & & Certified & Uncertified & \\
\hline \multicolumn{5}{|c|}{ Mean cost (Indian Rupees) by gestational age } \\
\hline \multicolumn{5}{|c|}{$\leq \mathbf{8}$ weeks } \\
\hline Minimum (n) & $114.3(7)$ & $482.2(23)$ & $256.7(38)$ & $318.3(68)$ \\
\hline Maximum (n) & $139.1(8)$ & $593.8(21)$ & $333.4(37)$ & $392.7(66)$ \\
\hline \multicolumn{5}{|l|}{ 9-12 weeks } \\
\hline Minimum (n) & $266.7(3)$ & $567.1(14)$ & $475.0(13)$ & $497.2(30)$ \\
\hline Maximum (n) & $366.7(3)$ & $670.8(12)$ & $595.8(12)$ & $603.7(27)$ \\
\hline \multicolumn{5}{|l|}{ 13-20 weeks } \\
\hline Minimum (n) & $100.0(1)$ & $730.0(5)$ & $1500.0(1)$ & $750.0(7)$ \\
\hline Maximum (n) & $200.0(1)$ & $1050.0(6)$ & $2000.0(1)$ & $1063.0(8)$ \\
\hline \multicolumn{5}{|l|}{ Charges include: } \\
\hline All drugs, medicines and lab tests & 11.1 & 41.6 & 42.2 & 35.6 \\
\hline Some drugs, medicines and lab tests & 27.8 & 37.5 & 26.7 & 29.9 \\
\hline No drugs, medicines or lab tests & 33.3 & 16.7 & 24.4 & 24.1 \\
\hline Other (i.e. depends on client's finances) & 27.8 & 4.2 & 6.7 & 10.4 \\
\hline Facilities charging for services (n) & 18 & 24 & 45 & 87 \\
\hline
\end{tabular}

a 18 public facilities (15 certified and 3 uncertified) reportedly do not charge for abortion services and are hence excluded from this analysis. 


\section{Social barriers to abortion service provision}

Table 3.6 describes the circumstances under which facilities reportedly provide abortion services. Only slightly more than one-quarter (27 percent) of facilities provide services if a woman presents by herself. Just under half ( 47 percent) provide abortion if a married woman has no children. Nearly twothirds (63 percent) provide abortions to unmarried women. In general, public facilities appear more likely to provide services in most circumstances. However, in the event a woman knows the sex of the foetus, 13 percent of private facilities reportedly provide abortion services compared to only six percent of public facilities.

\section{Consent procedures}

Eighty percent of head administrators report that their facility requires consent - either written (69 percent) or verbal (12 percent) - prior to performing an abortion (data not shown). Administrators at the 72 facilities requiring consent were asked from whom they take consent (Table 3.7). The majority ( 89 percent) obtain consent from the woman seeking the abortion (or her guardian in the case of a minor or mentally disabled

Table 3.6

Circumstances under which abortion services are provided by health sector (\%) a

\begin{tabular}{|l|c|c|c|}
\hline & Public & Private & Total \\
\hline Woman presents at clinic by herself & 33.3 & 23.2 & 26.7 \\
\hline Woman accompanied by friend but not family member & 86.1 & 50.7 & 62.9 \\
\hline Woman unmarried & 72.2 & 57.9 & 62.9 \\
\hline Woman widowed/separated/divorced & 80.6 & 62.3 & 68.6 \\
\hline Woman married and without children & 50.0 & 44.9 & 46.7 \\
\hline Woman has had one or more previous abortions & 63.9 & 56.5 & 60.0 \\
\hline Woman knows foetal sex & 5.6 & 13.0 & 10.5 \\
\hline Facilities $(\mathbf{n})$ & 36 & $\mathbf{6 9}$ & $\mathbf{1 0 5}$ \\
\hline
\end{tabular}

${ }^{\text {a }}$ May total to more than 100 percent because of multiple responses.

Table 3.7

Consent required for abortion procedure by health sector (\%) a

\begin{tabular}{|l|c|c|c|}
\hline & Public & Private & Total \\
\hline Woman herself/guardian & 84.6 & 91.3 & 88.8 \\
\hline Husband & 73.0 & 69.5 & 70.8 \\
\hline In-laws or parents & 11.5 & 19.6 & 16.6 \\
\hline Any close and responsible relatives & 38.5 & 19.6 & 26.4 \\
\hline Any accompanying person & 11.5 & 13.0 & 9.7 \\
\hline Facilities $(\mathbf{n})$ & $\mathbf{2 6}$ & $\mathbf{4 6}$ & $\mathbf{7 2}$ \\
\hline
\end{tabular}

${ }^{\text {a }}$ May total to more than 100 percent because of multiple responses. 
woman). While not required by law, nearly threequarters (71 percent) of facilities also obtain consent from a woman's husband before performing an abortion.

We also asked head administrators to share a copy of the consent form currently in use at their facility. Slightly less than half ( 45 percent) of the facilities that shared their consent forms had forms that indicated the specifics of the abortion procedure or the particular type of analgesia or anaesthesia used in the procedure ( 45 percent) (data not shown).

\section{Gestational age limits and caseloads} As indicated in Table 3.8, nearly half (47 percent) of the facilities in our sample only offer abortions for very early pregnancies (i.e. $\leq 8$ weeks). Just over one-tenth (13 percent) of facilities provide abortions through the second trimester. This practice, however, is more common in the public sector than in the private sector. Among the 14 facilities providing abortions in the second trimester, 85 percent were certified to provide pregnancy terminations (data not shown). Providers at the facilities that limited their abortion provision to 8 or 12 weeks' gestation were

Table 3.8

Gestational age limits for services by health sector (\%)

\begin{tabular}{|c|c|c|c|}
\hline & Public & Private & Total \\
\hline $\mathbf{8}$ 8 weeks & 38.9 & 50.7 & 46.7 \\
\hline 9-12 weeks & 44.4 & 37.7 & 40.0 \\
\hline 13-20 weeks & 16.7 & 11.6 & 13.3 \\
\hline Facilities (n) & $\mathbf{3 6}$ & $\mathbf{6 9}$ & $\mathbf{1 0 5}$ \\
\hline
\end{tabular}

\section{Table 3.9}

Abortion caseload in the three months preceding the study by health sector

\begin{tabular}{|c|c|c|c|}
\hline & Public & Private & Total \\
\hline \multicolumn{4}{|l|}{ Total number of abortions (\%) } \\
\hline 0 & 11.1 & 14.6 & 13.3 \\
\hline $1-10$ & 38.9 & 34.8 & 36.2 \\
\hline $11-25$ & 22.2 & 21.7 & 21.9 \\
\hline $26-100$ & 16.7 & 24.6 & 21.9 \\
\hline $101-218$ & 11.1 & 4.3 & 6.7 \\
\hline Mean number of abortions ${ }^{\text {a }}$ & 37.9 & 26.6 & 30.6 \\
\hline Facilities (n) & 36 & 69 & 105 \\
\hline
\end{tabular}

${ }^{a}$ Excludes the 13 facilities that reported providing no abortions in the three months preceding the study. 
Figure 3.2

Mean number of procedures provided in the three months preceding the survey by gestational age and clinic characteristics

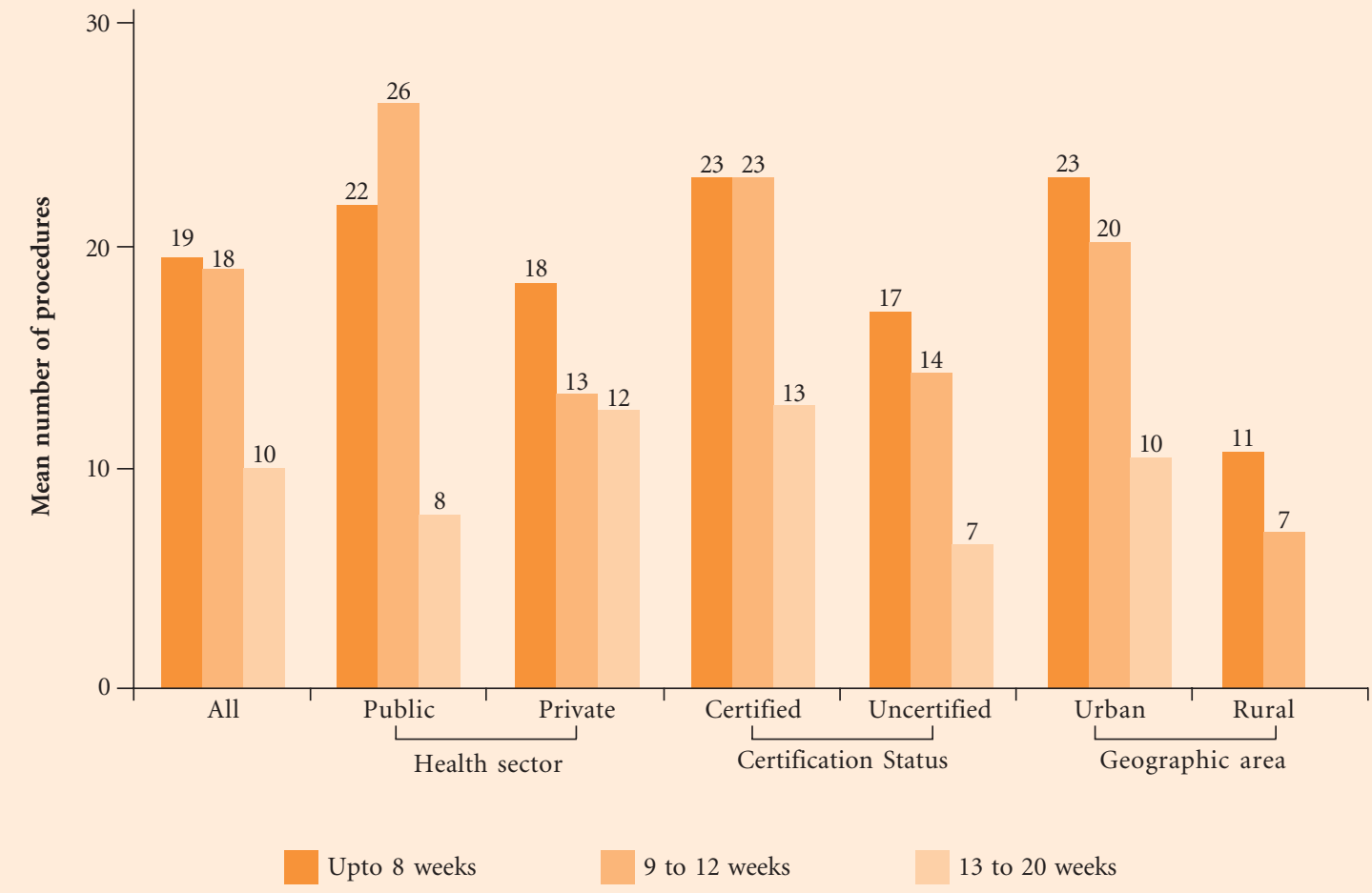

asked the reasons for this practice. More than half (54 percent) mention that the increased risk associated with abortions at later gestations deters them from offering this service. Nearly one-fourth (23 percent) believe that such abortions are illegal and 15 percent report that they do not have the skills to perform late first-trimester and/or second-trimester abortions (15 percent). Twelve percent of the providers who work at facilities where abortions are restricted to the earliest gestations indicate that this is done because they themselves do not approve of abortion at later gestations (data not shown).
Table 3.9 shows the number of abortions done in the three months preceding the study at the 105 sampled facilities. Caseloads were generally small in both the public and private sectors. Just over one-third (36 percent) of facilities performed between one and ten abortions and an additional 22 percent performed between eleven and 25 abortions during those three months. Few facilities ( 7 percent) performed very large numbers of abortions $(>100)$ and those that did were largely in the public sector (11 percent). 
We also examined gestational age variations in recent caseloads by different facility characteristics (Figure 3.2). Overall, first-trimester abortions were the most prevalent, with facilities averaging 19.4 abortions of $\leq 8$ weeks' gestation and 18.1 abortions of 9 to 12 weeks' gestation. Public sector facilities, however, average more late first-trimester abortions than early ones and those certified to provide abortions under the MTP Act provide, on average, the same number of early and late first-trimester abortions. Second-trimester abortions, while significantly more rare than first-trimester abortions across all facility types (with an overall average of 10.4 for the three months preceding the survey), are more common at private (as opposed to public), certified (as opposed to uncertified) and urban (as opposed to rural) facilities. Rural facilities have significantly smaller caseloads than those in urban areas, performing on average less than half the number of early first trimester-abortions approximately one-third the number of late first-trimester abortions as those in urban localities and no second-trimester abortions at all. 


\section{The Formal Sector: Provider Training, Methods and Standard Care}

A second objective of this study was to assess the training, skills and methods used by providers in the formal sector. This section presents the findings obtained from interviews with the 119 formal providers at the 105 sampled facilities.

\section{Provider skills and training}

Table 4.1 describes the qualifications and training of the 119 formal providers performing abortions in the facilities surveyed. Almost half (46 percent) of all providers interviewed have advanced degrees in gynaecology and thus are legally allowed to provide abortion services without additional training. An additional 17 percent of providers have a general medical degree or a specialisation in a branch of medicine aside from gynaecology but have received additional training in abortion and thus can legally perform MTPs. Over one-third (37 percent) of all providers interviewed have no formal training in abortion provision, however, rendering them uncertified to provide the service. Particularly in the private sector, a large proportion (35 percent) of

\section{Table 4.1}

Abortion-related qualifications and pre-service and in-service training in supportive areas by health sector (\%)

\begin{tabular}{|c|c|c|c|}
\hline & Public & Private & Total \\
\hline Gynaecologist & 40.4 & 50.0 & 46.2 \\
\hline Others certified in abortion provision & 21.3 & 13.9 & 16.8 \\
\hline MBBS plus formal abortion training & 14.9 & 12.5 & 13.4 \\
\hline $\begin{array}{l}\text { MS/MD in other branch of medicine plus } \\
\text { formal abortion training }\end{array}$ & 6.4 & 1.4 & 3.4 \\
\hline Uncertified in abortion provision & 38.3 & 36.1 & 37.0 \\
\hline MBBS & 17.0 & 1.4 & 7.6 \\
\hline $\mathrm{MD} / \mathrm{MS}$ in other branch of medicine & 2.1 & - & 0.8 \\
\hline BAMS/BUMS/DHMS & 19.2 & 34.7 & 28.6 \\
\hline \multicolumn{4}{|l|}{ Training in supportive area } \\
\hline Counselling and interpersonal communication & 25.5 & 30.6 & 28.6 \\
\hline Universal safety precautions & 36.2 & 33.3 & 34.5 \\
\hline Reproductive health & 44.7 & 33.3 & 37.8 \\
\hline Formal providers (n) & 47 & 72 & 119 \\
\hline
\end{tabular}


untrained formal providers are practitioners schooled in Indian systems of medicine. While not required to do so by law, relatively few formal providers in either the public or private sector have undergone training in counselling (29 percent), universal safety precautions (35 percent) or reproductive health (38 percent).

Over two-thirds ( 65 percent) of providers interviewed reported having received training in specific methods of abortion (data not shown). Table 4.2 describes the training of those 77 providers in more detail. Most have training in the provision of dilatation and curettage ( 77 percent), dilatation and evacuation (68 percent) or electric vacuum aspiration (61 percent). Less than one-third (27 percent) of these providers have been trained in the provision of medical abortion. For every abortion method, providers in the public sector are more likely to have formal training than their private-sector counterparts.

Formal providers were asked to describe the abortion techniques they use at different gestational ages (Table 4.3). At the earliest gestational ages ( $\leq 8$ weeks) over half (78 percent) of all providers report using dilatation and curettage (52 percent) or dilatation and evacuation (26 percent). A greater percentage of providers in the private sector use manual or electric vacuum aspiration than their public-sector counterparts for abortions of $\leq 8$ weeks' gestation. Most uncertified formal providers (81 percent) use other methods, largely non-surgical methods, for early first-trimester abortions.

For abortions between 9 and 12 weeks' gestational age, over two-thirds (64 percent) of formal providers use dilatation and curettage and almost half (45 percent) use dilatation and evacuation. Again, a slightly greater percentage of private providers (48 percent) than public providers (39 percent) use manual or electric vacuum aspiration at this gestational age. Only 15 providers, all certified, reported on the procedures used to perform abortions in the second trimester. At this gestational

Table 4.2

Training in methods of abortion by health sector (\%)a

\begin{tabular}{|l|c|c|c|}
\hline & Public & Private & Total \\
\hline Manual vacuum aspiration & 69.0 & 52.1 & 58.4 \\
\hline Electric vacuum aspiration & 72.4 & 54.2 & 61.0 \\
\hline Dilatation and curettage & 86.2 & 70.8 & 76.6 \\
\hline Dilatation and evacuation & 79.3 & 60.4 & 67.5 \\
\hline Extra-amniotic method & 62.1 & 41.7 & 49.4 \\
\hline Intra-amniotic method & 48.3 & 33.3 & 39.0 \\
\hline Medical abortion & 31.0 & 25.0 & 27.3 \\
\hline Formal trained providers $(\mathbf{n})$ & $\mathbf{2 9}$ & $\mathbf{4 8}$ & $\mathbf{7 7}$ \\
\hline
\end{tabular}

${ }^{a}$ May total to more than 100 percent because of multiple responses. 


\section{Table 4.3}

Technique used to perform abortions at different gestational ages by health sector and provider certification status $(\%)$

\begin{tabular}{|c|c|c|c|c|c|}
\hline & \multicolumn{2}{|c|}{ Health sector } & \multicolumn{2}{|c|}{ Provider certification status } & \multirow[b]{2}{*}{ Total } \\
\hline & Public & Private & Certified & Uncertified & \\
\hline \multicolumn{6}{|l|}{ Upto 8 weeks ${ }^{a}$} \\
\hline Manual vacuum aspiration & 12.8 & 21.9 & 26.4 & - & 18.4 \\
\hline Electric vacuum aspiration & 20.5 & 21.9 & 27.8 & 6.5 & 21.4 \\
\hline Dilatation and curettage & 61.5 & 46.9 & 66.7 & 19.4 & 52.4 \\
\hline Dilatation and evacuation & 30.8 & 23.4 & 34.7 & 6.5 & 26.2 \\
\hline Other & 20.5 & 29.7 & 2.8 & 80.6 & 26.2 \\
\hline Formal providers (n) & 47 & 72 & 77 & 42 & 119 \\
\hline \multicolumn{6}{|l|}{$9-12$ weeks $^{\text {a }}$} \\
\hline Manual vacuum aspiration & 15.4 & 14.8 & 16.3 & - & 15.1 \\
\hline Electric vacuum aspiration & 23.1 & 33.3 & 28.6 & 25.0 & 28.3 \\
\hline Dilatation and curettage & 65.4 & 63.0 & 65.3 & 50.0 & 64.2 \\
\hline Dilatation and evacuation & 46.2 & 44.4 & 49.0 & - & 45.3 \\
\hline Other & 7.7 & 7.4 & 4.1 & 50.0 & 7.5 \\
\hline Formal providers (n) & 26 & 27 & 49 & 4 & 53 \\
\hline \multicolumn{6}{|l|}{$13-20$ weeks $^{\text {a }}$} \\
\hline Manual vacuum aspiration & - & 16.7 & 6.7 & - & 6.7 \\
\hline Electric vacuum aspiration & 11.1 & 16.7 & 13.3 & - & 13.3 \\
\hline Dilatation and curettage & 66.7 & 33.3 & 53.3 & - & 53.3 \\
\hline Dilatation and evacuation & 77.8 & 33.3 & 60.0 & - & 60.0 \\
\hline Extra-amniotic instillation & 22.2 & 33.3 & 26.7 & - & 26.7 \\
\hline Other & 11.1 & 16.7 & 13.3 & - & 13.3 \\
\hline Formal providers (n) & 9 & 6 & 15 & - & 15 \\
\hline
\end{tabular}

a May total to more than 100 percent because of multiple responses.

age, most providers use either dilatation and curettage (53 percent) or dilatation and evacuation (60 percent).

Formal providers were also asked about the methods of pain control employed at different gestational ages (Table 4.4). Most providers use analgesia for pain control in abortions upto 8 weeks' gestation (61 percent) and between 9 and 12 weeks' gestation (81 percent). A significant proportion, however, use general anaesthesia ( 23 percent) or no method of pain control (23 percent) for abortions at very early gestations. A handful (4 percent) of providers do not provide any medication to manage pain when performing abortions in the late first 


\section{Table 4.4}

Method of pain control used at different gestational ages by health sector (\%)

\begin{tabular}{|c|c|c|c|}
\hline Method of pain control by gestational age & Public & Private & Total \\
\hline \multicolumn{4}{|l|}{ Upto 8 weeks a } \\
\hline Analgesia/anxiolytic/sedation & 66.7 & 57.8 & 61.2 \\
\hline Local anaesthesia & 17.9 & 17.2 & 17.5 \\
\hline General anaesthesia & 12.8 & 29.7 & 23.3 \\
\hline Nothing & 17.9 & 26.6 & 23.3 \\
\hline Formal providers (n) & 47 & 72 & 119 \\
\hline \multicolumn{4}{|l|}{$9-12$ weeks $^{a}$} \\
\hline Analgesia/anxiolytic/sedation & 80.8 & 81.5 & 81.1 \\
\hline Local anaesthesia & 11.5 & 11.1 & 11.3 \\
\hline General anaesthesia & 26.9 & 33.3 & 30.2 \\
\hline Nothing & 3.8 & 3.7 & 3.8 \\
\hline Formal providers (n) & 26 & 27 & 53 \\
\hline \multicolumn{4}{|l|}{ 13-20 weeks ${ }^{a}$} \\
\hline Analgesia/anxiolytic/sedation & 77.8 & 83.3 & 80.0 \\
\hline Local anaesthesia & 11.1 & - & 6.7 \\
\hline General anaesthesia & 44.4 & 50.0 & 46.7 \\
\hline Formal providers (n) & 9 & 6 & 15 \\
\hline
\end{tabular}

trimester either. For second-trimester abortions, most providers use analgesia ( 80 percent) or general anaesthesia (47 percent).

\section{Length of stay}

We asked providers about the average time that women are kept in the clinic or hospital after their abortions (Figure 4.1). Overall, women seeking services in the public sector are admitted for longer periods of time than those seeking services in the private sector, particularly for later abortions. Indeed, women who obtain second-trimester abortions in the public sector stay in the clinic or hospital for an average of 28.0 hours, while those who obtain the service in the private sector are released on average 12.9 hours after being admitted.

\section{Referral Patterns}

Almost half (43 percent) of all formal providers perform all abortions that are requested at their facility (data not shown). Of the 66 providers who refer some cases to other facilities/providers, most do so when women present for second trimester abortions ( 82 percent), have medical risk factors (38 percent), are unmarried (23 percent) or desire a sex-selective abortion (20 percent). Referrals are made 


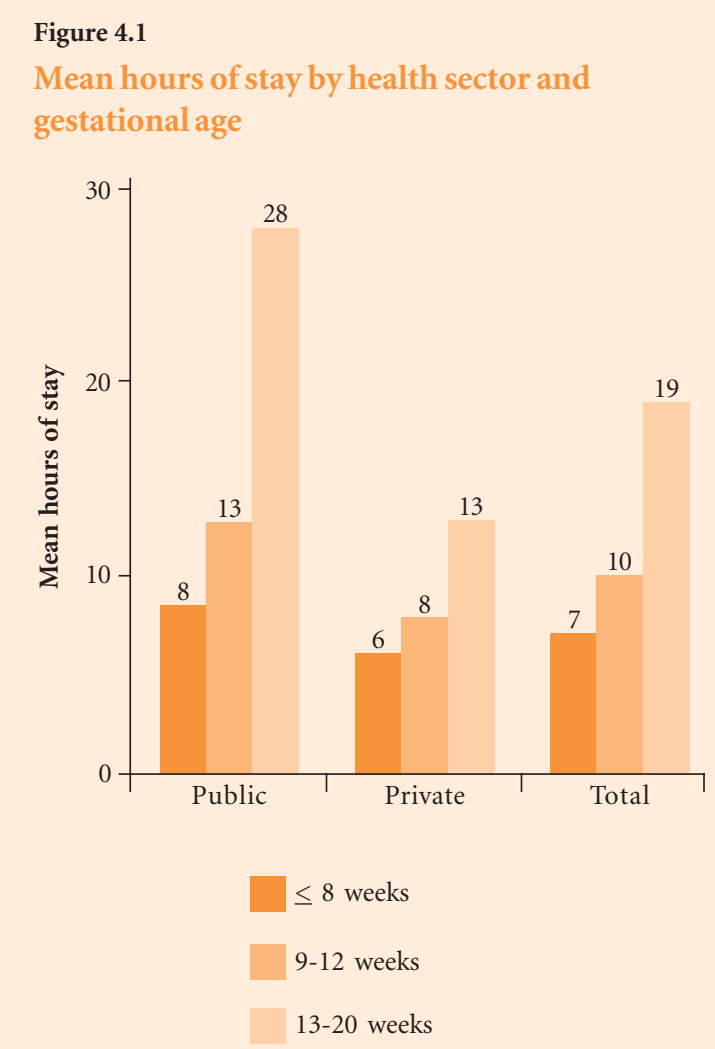

largely to district hospitals (53 percent), but in some cases to community health centres (20 percent) or municipal hospitals (15 percent). Twenty percent of referring providers have a formal arrangement with the referral centre (data not shown).

\section{Pre-abortion care and counselling}

Table 4.5 shows the standard care reportedly provided before the abortion procedure. The majority of formal providers use a urine pregnancy test (67 percent) and/or conduct a pelvic exam (58 percent) to confirm pregnancy. Both methods of pregnancy confirmation are more common in the public than the private sector. Nine percent of all providers do not confirm the pregnancy at all before providing an abortion. Almost two-thirds (62 percent) of all providers also measure haemoglobin levels and 40 percent do blood typing before providing abortions. Most formal providers counsel patients about potential pain or discomfort during the procedure (66 percent) or possible complications ( 74 percent).

\section{Post-abortion care and counselling}

Providers also described the standard examinations they perform and counselling they offer after the abortion procedure (Table 4.6). Most providers (71 percent) perform a general physical examination before discharging the patient. Relatively few perform a pelvic (19 percent) or abdominal exam (21 percent). Eighty-five percent of providers in the public sector instruct clients when to return for routine follow-up compared to only 67 percent of providers in private facilities. Fifty percent of all providers tell clients how to take any prescribed medicine.

Relatively few providers offer their clients information about diet (28 percent), work (18 percent) or sexual intercourse following the procedure (19 percent). Most providers ( 89 percent) advise clients to return immediately in the event of excessive bleeding. Substantially fewer providers request clients to return in the case of severe abdominal pain or distension (49 percent), vomiting (22 percent), fever (36 percent) or the presence of foul-smelling discharge (20 percent). 
Formal providers also specified the drugs routinely prescribed after an abortion procedure (Table 4.7). Almost two-thirds (62 percent) of formal providers prescribe antibiotics post abortion. Almost one-third recommend either painkillers (31 percent) or iron supplements (22 percent). In the private sector, about one-tenth (11 percent) of formal providers prescribe no medication post procedure.
Most formal providers report discussing contraception with their clients after their abortions (Table 4.8). Formal providers in the public sector are substantially more likely to insist on the adoption of a contraceptive method post abortion ( 53 percent) than providers in the private sector (35 percent). Among the 50 providers who report insisting on the adoption of contraception post abortion, most require the adoption of a

\section{Table 4.5}

Standard pre-abortion care by health sector (\%)

\begin{tabular}{|c|c|c|c|}
\hline & Public & Private & Total \\
\hline \multicolumn{4}{|l|}{ Method used to confirm pregnancy a } \\
\hline Abdominal examination & 25.5 & 18.1 & 21.0 \\
\hline Ultrasound & 6.4 & 19.4 & 14.3 \\
\hline Pelvic examination & 72.3 & 51.4 & 59.7 \\
\hline Urine pregnancy test & 72.3 & 63.9 & 67.2 \\
\hline Other & 10.6 & 12.5 & 11.8 \\
\hline None & 6.4 & 11.1 & 9.2 \\
\hline \multicolumn{4}{|l|}{ Laboratory test ${ }^{\mathrm{a}}$} \\
\hline Haemoglobin & 68.1 & 58.3 & 62.2 \\
\hline Blood group & 36.2 & 43.1 & 40.3 \\
\hline Urine for albumin and sugar & 70.2 & 52.8 & 59.7 \\
\hline Venereal Disease Research Laboratory & 4.3 & 11.1 & 8.4 \\
\hline HIV & - & 1.4 & 0.8 \\
\hline Other & 4.3 & 8.3 & 6.7 \\
\hline None & 14.9 & 23.6 & 20.2 \\
\hline \multicolumn{4}{|l|}{ Counselling a } \\
\hline Pain/discomfort during procedure & 72.3 & 62.5 & 66.4 \\
\hline Possible complications & 76.6 & 72.2 & 73.9 \\
\hline Return of fertility & 10.6 & 18.1 & 15.1 \\
\hline Other & 10.6 & 8.3 & 9.2 \\
\hline None & 2.1 & 2.8 & 2.5 \\
\hline Formal providers (n) & 47 & 72 & 119 \\
\hline
\end{tabular}

${ }^{a}$ May total to more than 100 percent because of multiple responses. 
permanent or long-term method, such as tubectomy (52 percent) or an intrauterine device (62 percent).

\section{Management of abortion complications}

Table 4.9 describes the management of abortion complications as reported by formal providers. In the event of excessive bleeding due to retained products of conception and/or infection, more than half (60 percent) of providers report they manage the complication onsite. Providers in the private sector (33 percent) are slightly more likely to refer such cases to a hospital compared to their public sector

\section{Table 4.6}

Standard post-abortion care by health sector (\%)

\begin{tabular}{|c|c|c|c|}
\hline & Public & Private & Total \\
\hline \multicolumn{4}{|c|}{ Examination $(s)$ conducted at time of discharge ${ }^{\text {a }}$} \\
\hline General physical examination & 74.5 & 68.1 & 70.6 \\
\hline Pelvic examination & 25.5 & 15.3 & 19.3 \\
\hline Abdominal examination & 29.8 & 15.3 & 21.0 \\
\hline Other & 6.4 & 12.5 & 10.1 \\
\hline None & 19.1 & 23.6 & 21.8 \\
\hline \multicolumn{4}{|c|}{ Instruction(s) provided at time of discharge ${ }^{a}$} \\
\hline When to return for routine follow-up & 85.1 & 66.7 & 73.9 \\
\hline Problems to expect & 25.5 & 25.0 & 25.2 \\
\hline Danger signs and what to do about them & 36.2 & 30.6 & 32.8 \\
\hline How to take prescribed medicine & 53.2 & 47.2 & 49.6 \\
\hline Instruction about diet & 29.8 & 26.4 & 27.7 \\
\hline Instruction about work & 17.0 & 18.1 & 17.6 \\
\hline Instruction about sexual intercourse & 23.4 & 16.7 & 19.3 \\
\hline Other & 4.3 & 4.2 & 4.2 \\
\hline None & 4.3 & 12.5 & 9.2 \\
\hline \multicolumn{4}{|c|}{$\begin{array}{l}\text { Circumstances under which clients are advised } \\
\text { to return to clinic immediately }{ }^{\text {a }}\end{array}$} \\
\hline Excessive bleeding & 89.4 & 88.9 & 89.1 \\
\hline Severe abdominal pain or distension & 57.4 & 43.1 & 48.7 \\
\hline Vomiting & 21.3 & 22.2 & 21.8 \\
\hline Fever & 34.0 & 37.5 & 36.1 \\
\hline Foul-smelling discharge & 17.0 & 22.2 & 20.2 \\
\hline Any serious condition & 14.9 & 11.1 & 12.6 \\
\hline Other & 12.8 & 9.7 & 10.9 \\
\hline Formal providers (n) & 47 & 72 & 119 \\
\hline
\end{tabular}

${ }^{a}$ May total to more than 100 percent because of multiple responses. 
Table 4.7

Drugs routinely prescribed after abortion by health sector (\%) a

\begin{tabular}{|l|r|r|r|}
\hline & Public & Private & Total \\
\hline Antibiotic & 66.0 & 59.7 & 62.2 \\
\hline Analgesic & 29.7 & 31.9 & 31.0 \\
\hline Antispasmodic & 8.5 & 5.6 & 6.7 \\
\hline Uterotonic & 17.0 & 15.3 & 16.0 \\
\hline Anti-inflammatory & 4.3 & 11.1 & 8.4 \\
\hline Vitamins & 10.6 & 19.5 & 16.0 \\
\hline Iron & 21.3 & 22.2 & 21.8 \\
\hline Others & 4.3 & 2.8 & 3.4 \\
\hline None & 4.3 & 11.1 & 8.4 \\
\hline Formal providers $(\mathbf{n})$ & $\mathbf{4 7}$ & $\mathbf{7 2}$ & $\mathbf{1 1 9}$ \\
\hline
\end{tabular}

${ }^{a}$ May total to more than 100 percent because of multiple responses.

Table 4.8

Post-abortion contraceptive counselling by health sector (\%)

\begin{tabular}{|l|c|c|c|}
\hline & Public & Private & Total \\
\hline Discuss contraception with clients & 97.9 & 88.9 & 92.4 \\
\hline Insist on adoption of contraception & 53.2 & 34.7 & 42.0 \\
\hline Formal providers (n) & $\mathbf{4 7}$ & $\mathbf{7 2}$ & $\mathbf{1 1 9}$ \\
\hline $\begin{array}{l}\text { Insist on the adoption of the following method(s): }{ }^{\mathbf{a}} \\
\text { Female sterilisation }\end{array}$ & 52.0 & 52.0 & 52.0 \\
\hline $\begin{array}{l}\text { Male sterilisation } \\
\text { Intrauterine device }\end{array}$ & 20.0 & 4.0 & 12.0 \\
\hline $\begin{array}{l}\text { Oral contraceptive pills } \\
\text { Condom }\end{array}$ & 64.0 & 60.0 & 62.0 \\
\hline $\begin{array}{l}\text { Injectables } \\
\text { Formal providers who insist on the adoption } \\
\text { of contraception (n) }\end{array}$ & 52.0 & 64.0 & 58.0 \\
\hline
\end{tabular}

${ }^{a}$ May total to more than 100 percent because of multiple responses. 


\section{Table 4.9}

Management approaches for abortion complications by health sector (\%)

\begin{tabular}{|l|r|r|r|}
\hline & Public & Private & Total \\
\hline $\begin{array}{l}\text { Excessive bleeding due to retained products of } \\
\text { conception and/or infection }\end{array}$ & & & \\
\hline $\begin{array}{l}\text { Refer immediately to hospital } \\
\text { Initiate treatment, stabilise the patient and then refer }\end{array}$ & 21.3 & 33.3 & 28.6 \\
\hline $\begin{array}{l}\text { Manage onsite } \\
\text { Others }\end{array}$ & 19.1 & 5.6 & 10.9 \\
\hline $\begin{array}{l}\text { Perforation leading to peritonitis } \\
\text { Refer immediately to hospital }\end{array}$ & - & 59.7 & 59.7 \\
\hline $\begin{array}{l}\text { Initiate treatment, stabilise the patient and then refer } \\
\text { Manage onsite }\end{array}$ & 17.1 & 1.4 & 0.8 \\
\hline Formal providers (n) & 40.4 & 47.5 & 45.4 \\
\hline
\end{tabular}

counterparts (21 percent). In the event of perforation leading to peritonitis, a little less than half of providers refer immediately to a hospital (45 percent) or manage the case onsite ( 45 percent).

\section{New reproductive health technologies}

Tables 4.10 and 4.11 show formal providers'

knowledge of new reproductive health technologies including medical abortion and emergency

\section{Table 4.10}

Awareness and prescription of medical abortion by health sector $(\%)$

\begin{tabular}{|c|c|c|c|}
\hline & Public & Private & Total \\
\hline Heard of medical abortion (\%) & 56.8 & 57.1 & 57.0 \\
\hline Heard of mifepristone, Mifegest or Mifeprin (\%) & 54.1 & 50.8 & 52.0 \\
\hline Heard of misoprostol, Cytotec, Cytolog or Zitotec (\%) & 48.6 & 47.6 & 48.0 \\
\hline Formal providers $(\mathbf{n})$ & 37 & 63 & 100 \\
\hline Know whether mifepristone, Mifegest or Mifeprin are available locally & 80.9 & 77.8 & 78.9 \\
\hline Know whether misoprostol, Cytotec, Cytolog or Zitotec are available locally & 76.2 & 72.2 & 73.7 \\
\hline Used mifepristone, Mifegest or Mifeprin & 23.8 & 30.6 & 28.1 \\
\hline Used misoprostol, Cytotec, Cytolog or Zitotec & 23.8 & 33.3 & 29.8 \\
\hline Formal providers familiar with medical abortion (n) & 21 & 36 & 57 \\
\hline
\end{tabular}


Table 4.11

Awareness and prescription of emergency contraception by health sector (\%)

\begin{tabular}{|l|c|c|c|}
\hline & Public & Private & Total \\
\hline $\begin{array}{l}\text { Aware of emergency contraception } \\
\text { Formal providers (n) }\end{array}$ & 61.7 & 58.3 & 59.7 \\
\hline $\begin{array}{l}\text { Provide emergency contraception } \\
\text { Received request for emergency contraception in three months } \\
\text { preceding the study }\end{array}$ & 47 & 72 & 119 \\
\hline \begin{tabular}{l} 
Formal providers familiar with emergency contraception \\
\hline
\end{tabular} & 62.1 & 64.3 & 63.3 \\
\hline
\end{tabular}

contraception. As indicated in Table 4.10, over half of providers are reportedly familiar with medical abortion (57 percent). Slightly fewer but still a significant proportion of providers know of the antiprogestin drug mifepristone and/or the Indianmanufactured versions Mifegest and Mifeprin (52 percent). Similarly, 48 percent of providers have heard of the prostaglandin misoprostol and/or the trademarked versions Cytotec, Cytolog or Zitotec. Among the 57 providers familiar with medical abortion, mifepristone or misoprostol, a large proportion know whether these products are available locally (mifepristone 79 percent; misoprostol 74 percent). A fair number of those providers report having used mifepristone (29 percent) or misoprostol (30 percent).

More than half ( 60 percent) of providers in our sample are familiar with emergency contraception (Table 4.11). Among those familiar with the method, nearly two-thirds (63 percent) provide post-coital contraceptives to their clients and nearly one-third (30 percent) report having received a request for such contraceptives in the three months preceding the study.

\section{Familiarity with and attitudes about abortion legislation}

Since a provider's knowledge of and attitudes regarding abortion may influence when and how services are provided, respondents were asked about their knowledge of the legality of abortion and whether they would endorse abortion in various circumstances. Table 4.12 describes formal providers' familiarity with the MTP Act. Most providers are aware that abortion is legal in the case of contraceptive failure (91 percent), when a pregnancy is a result of rape (92 percent), when a woman's health is endangered by the pregnancy ( 96 percent) or when there is a strong chance of foetal malformation (92 percent). However, only 71 percent of providers know that abortion is legal if the woman is unmarried. While not required by law, over half (55 percent) of the providers interviewed believe it is necessary to obtain the consent of the husband before performing an abortion procedure (data not shown).

Formal providers were also asked about the circumstances under which they endorse abortion (Table 4.13). Most providers feel a woman should be able to have an abortion if her health is endangered 
Table 4.12

Circumstances under which providers believe abortion is legal by health sector (\%)a

\begin{tabular}{|l|c|c|c|}
\hline & Public & Private & Total \\
\hline Unmarried woman & 74.5 & 69.4 & 71.4 \\
\hline Contraceptive failure & 93.6 & 88.9 & 90.8 \\
\hline Pregnancy resulting from rape & 93.6 & 91.7 & 92.4 \\
\hline Woman's health endangered by pregnancy & 95.7 & 95.8 & 95.8 \\
\hline Chance of foetal malformation & 91.5 & 93.1 & 92.4 \\
\hline Formal providers $(\mathbf{n})$ & $\mathbf{4 7}$ & $\mathbf{7 2}$ & $\mathbf{1 1 9}$ \\
\hline
\end{tabular}

${ }^{\text {a }}$ May total to more than 100 percent because of multiple responses.

\section{Table 4.13}

Circumstances under which providers endorse abortion by health sector (\%) a

\begin{tabular}{|l|r|r|r|}
\hline & Public & Private & Total \\
\hline Woman does not want another child & 93.6 & 79.2 & 84.9 \\
\hline Woman cannot afford child & 93.6 & 87.5 & 89.9 \\
\hline Unmarried woman & 97.9 & 90.3 & 93.3 \\
\hline Contraceptive failure & 95.7 & 90.3 & 92.4 \\
\hline Rape & 100.0 & 95.8 & 97.5 \\
\hline Woman's health endangered by pregnancy & 95.7 & 100.0 & 98.3 \\
\hline Foetal malformation & 97.9 & 95.8 & 96.6 \\
\hline Female foetus & 2.1 & 4.2 & 3.4 \\
\hline Male foetus & 2.1 & 5.6 & 4.2 \\
\hline Formal providers $(\mathbf{n})$ & $\mathbf{4 7}$ & $\mathbf{7 2}$ & $\mathbf{1 1 9}$ \\
\hline
\end{tabular}

${ }^{a}$ May total to more than 100 percent because of multiple responses.

(98 percent), when there is the chance of foetal defect (97 percent) and in the case of rape (98 percent) or contraceptive failure ( 92 percent). The vast majority of providers also believe that a woman should be able to obtain an abortion if she is unmarried, although providers working in public facilities are more supportive of abortion in this situation (97 percent) than those in private facilities ( 90 percent). Slightly fewer providers feel abortion is acceptable if a woman does not want another child ( 85 percent) or cannot afford another child ( 90 percent). Few providers endorse sexselective abortion (female foetus 3.4 percent; male foetus 4.2 percent), particularly in the public sector (female foetus 2.1 percent; male foetus 2.1 percent). 


\section{The Informal Sector: Personnel and Services}

This section presents our findings on the training of and abortion services provided by informal providers.

\section{Profile of informal abortion providers}

Table 5.1 shows the socio-demographic characteristics of the 489 informal providers sampled. The informal providers in our study are largely (66 percent) male

\section{Table 5.1}

Profile of informal providers interviewed

\begin{tabular}{|l|l|}
\hline Age (mean years) & 38.4 \\
\hline Sex (\%) & \\
\hline Male & 66.1 \\
\hline Female & 33.9 \\
\hline Education (\%) & \\
\hline None or primary school & 23.9 \\
\hline Middle or high school & 48.1 \\
\hline Graduate and/or postgraduate & 28.0 \\
\hline Area (\%) & \\
\hline Urban & 41.3 \\
Rural & 58.7 \\
\hline Informal providers (n) & 489 \\
\hline
\end{tabular}

Table 5.2

Provider qualifications by district (\%)

\begin{tabular}{|c|c|c|c|c|c|c|c|}
\hline & Alwar & Bhilwara & Bikaner & Karauli & Pali & Tonk & Total \\
\hline $\begin{array}{l}\text { Auxiliary nurse midwife/nurse/ } \\
\text { lady health workers }\end{array}$ & 11.3 & 15.8 & 10.0 & 22.2 & 18.7 & 18.5 & 14.1 \\
\hline Dai/community health worker & 21.1 & 44.7 & 16.2 & 17.8 & 29.2 & 23.1 & 22.9 \\
\hline Chemist/compounder/male health worker & 31.9 & 26.3 & 47.5 & 33.3 & 39.6 & 36.9 & 35.6 \\
\hline Rural medical practitioner/village practitioner & 35.7 & 13.2 & 26.3 & 26.7 & 12.5 & 21.5 & 27.4 \\
\hline Informal providers (n) & 213 & 38 & 80 & 45 & 48 & 65 & 489 \\
\hline
\end{tabular}

and average 38 years of age. Almost one-half (48 percent) of all informal providers we interviewed have a middle- or high-school education, and over half (59 percent) are located in rural areas.

Table 5.2 describes the types of informal providers interviewed by district. As was the case with the formal-sector sample, the sample of informal providers is skewed largely towards Alwar district, with substantially fewer such providers interviewed in the other five districts. Over one-third (36 percent) of the providers identify themselves as chemists, compounders or male health workers. Other types of informal providers included in our sample are rural medical practitioners or village practitioners (27 percent), dais or community health workers (23 percent) and auxiliary nurse midwives, lady health workers or nurses (14 percent).

\section{Training}

Informal providers were asked about the extent and duration of their training in health care (Table 5.3). Almost half ( 49 percent) of the informal providers have no formal training in health care. 
Table 5.3

\section{Training in health care (\%)}

\begin{tabular}{l|r|}
\hline No formal training & 49.1 \\
Short course & 7.1 \\
Certificate & 13.1 \\
Diploma & 24.7 \\
Degree & 6.0 \\
\hline Informal providers (n) & $\mathbf{4 8 9}$ \\
\hline
\end{tabular}

One-quarter (25 percent) of informal providers have completed a diploma in some health specialty, and fewer have finished a certificate (13 percent) or short course ( 7 percent). Of those who have completed a formal training course, they completed an average of 24 months of training. Among respondents who had received no formal training, almost 79 percent received on-the-job training at a clinic or medical shop (data not shown).

\section{Location of services and manner in which clients learn of them}

Data on the location and timing of services provided by informal providers are shown in Table 5.4.

Not surprisingly given the number of chemists in the sample, 29 percent of respondents consult with clients at a chemist shop or a private clinic/shop (14 percent). Almost one-quarter (24 percent) of all respondents meet with clients in a hospital setting - either a government hospital (7 percent) or a private hospital (17 percent). Slightly more than one-quarter (26 percent) of informal providers provide services in their client's home.
Table 5.4

Availability of services and identification by client (\%)

\begin{tabular}{|l|r|}
\hline Location of consultation $^{\text {a }}$ & \\
\hline Government hospital & 6.5 \\
\hline Private hospital & 17.0 \\
Chemist shop & 28.8 \\
\hline In private clinic/shop & 26.2 \\
At client's home & 13.7 \\
Own house & 7.0 \\
Other & 3.5 \\
\hline
\end{tabular}

Number of days services provided

$\leq 6$ days

18.0

7 days

Methods through which clients learn

of services $^{\text {a }}$

Referred by other women/men

29.0

Referred by other providers

11.2

Well known in community

78.5

From the community

27.6

Local advertisements

15.3

Others

Informal providers (n)

489

${ }^{a}$ May total to more than 100 percent because of multiple responses.

Most informal providers ( 82 percent) provide services daily. Over three-quarters (79 percent) report that clients learn of their services because they are "well known in the area" or are from the community in which they practise (28 percent). Only eleven percent of informal providers report that clients are referred through other providers. 


\section{Treatments offered to women with delayed menstruation or unwanted pregnancy}

Figure 5.1 shows the treatment and procedures offered by informal providers to women with delayed menstruation or unwanted pregnancy. The vast majority ( 75 percent) of informal providers give women tablets in these circumstances. Informal providers also provide herbs (26 percent) or injections (10 percent), apply pressure or massage (11 percent), and far more rarely, use instruments ( 5 percent) to provoke an abortion. Data not shown indicates that providers using instrumentation are largely female, either dais or auxiliary nurse midwives.

As Table 5.5 reveals, the average number of cases treated per month varies depending on the method of abortion used. Indeed, the 129 providers who use herbs to treat delayed menstruation or unwanted pregnancy average 4.3 cases per month, while the 29 providers who provide abortion using instrumentation treat an average of 9.7 cases per month. Regardless of the method used, all informal providers report mean success rates of less than 60 percent. The 29 providers who rely on instruments report the highest mean success rate $(60$ percent) while the 371 using tablets report the lowest (41 percent). The mean minimum and maximum charges vary little in the case of pressure or massage, herbs, tablets and injections, generally ranging between 30 and 60 Indian Rupees. Providers who use instrumentation, however, report far higher costs and a larger range in costs, with a mean minimum of 197 Indian Rupees and a mean maximum of 593 Indian Rupees.

\section{Counselling practices}

Table 5.6 describes the types of information informal providers give to women treated for delayed menstruation or unwanted pregnancy. Most informal providers inform clients about how the treatment works (83 percent) or the side effects or possible complications of the treatment (70 percent). Some informal providers also offer additional information about dietary restrictions or recommendations

Figure 5.1

Treatments and procedures offered for delayed menstruation or unwanted pregnancy

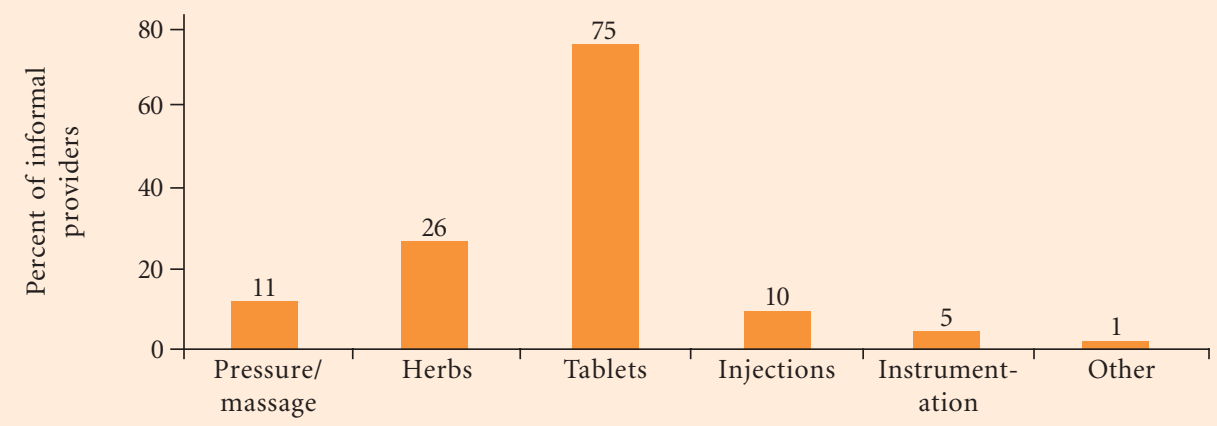


Table 5.5

Caseloads, success rates and costs by method of treatment/procedure

\begin{tabular}{|l|c|c|c|c|c|}
\hline & Pressure/massage & Herbs & Tablets & Injections & Instrumentation \\
\hline Women treated per month (mean number) & 5.4 & 4.3 & 7.2 & 5.3 & 9.7 \\
\hline $\begin{array}{l}\text { Mean reported success rate (\%) } \\
\text { Mean cost (Indian Rupees) }\end{array}$ & 47.3 & 57.1 & 40.8 & 48.6 & 59.5 \\
\hline $\begin{array}{l}\text { Minimum } \\
\text { Maximum }\end{array}$ & 30.67 & 32.20 & 33.53 & 47.22 & 197.24 \\
\hline Informal providers (n) & 56.56 & 57.25 & 60.86 & 73.98 & 593.38 \\
\hline
\end{tabular}

Table 5.6

Counselling practices (\%)

\begin{tabular}{|c|c|}
\hline \multicolumn{2}{|c|}{ Advise women on how treatment works } \\
\hline Yes & 82.8 \\
\hline Sometimes & 3.9 \\
\hline Never & 13.3 \\
\hline \multicolumn{2}{|c|}{$\begin{array}{l}\text { Advise women about side effects/ } \\
\text { possible complications }\end{array}$} \\
\hline Yes & 70.1 \\
\hline Sometimes & 4.6 \\
\hline Never & 25.3 \\
\hline \multicolumn{2}{|c|}{ Provide additional advice on: ${ }^{a}$} \\
\hline $\begin{array}{l}\text { How to take the prescribed } \\
\text { medicines/treatment }\end{array}$ & 27.6 \\
\hline Diet & 43.1 \\
\hline Physical activity & 19.6 \\
\hline Sexual intercourse & 9.6 \\
\hline Hygiene & 5.5 \\
\hline Other topics & 2.5 \\
\hline No additional advice given & 16.6 \\
\hline Informal providers (n) & 489 \\
\hline
\end{tabular}

${ }^{a}$ May total to more than 100 percent because of multiple responses.
(43 percent) or how to take the prescribed medicine or treatment (28 percent). Fewer offer instructions regarding sexual intercourse (10 percent).

Some informal providers (17 percent) offer no advice to women who accept services from them.

Informal providers were also asked whether they advise women with delayed menstruation or unwanted pregnancy to use contraception after their treatment. About four-fifths (78 percent) reportedly provide such advice (data not shown). Among the 394 informal providers who discuss contraception with their clients, most recommend condoms (85 percent) or oral contraceptives(76 percent). Slightly fewer informal providers suggest use of intrauterine devices ( 52 percent) or female sterilisation (37 percent) (Table 5.7).

\section{New reproductive health technologies}

In general, informal providers are unaware of new reproductive health technologies such as medical abortion and emergency contraception. Only 13 percent have heard of medical abortion (Table 5.8). Fewer providers are aware of the antiprogestin drug 
mifepristone and/or the Indian-manufactured versions Mifegest and Mifeprin (6 percent), or the prostaglandin misoprostol and/or the trademarked versions Cytotec, Cytolog or Zitotec (6 percent). Among the 62 informal providers familiar with medical abortion mifepristone or misoprostol, 42 and 39 percent, respectively, know whether the antiprogestin mifepristone or the prostaglandin

Table 5.7

Methods of contraception recommended
to clients $(\%)^{\text {a }}$

\begin{tabular}{l|c|}
\hline Female sterilisation & 37.0 \\
\hline Male sterilisation & 10.2 \\
Intrauterine device & 52.1 \\
Oral contraceptive pills & 75.8 \\
Condom & 84.6 \\
Injectables & 5.5 \\
Rhythm method & 4.4 \\
\hline $\begin{array}{l}\text { Informal providers who discuss } \\
\text { contraception with clients (n) }\end{array}$ & $\mathbf{3 8 4}$ \\
\hline
\end{tabular}

${ }^{a}$ May total to more than 100 percent because of multiple responses. misoprostol is available locally. Few of the 62 informal providers aware of medical abortion have actually used any of these drugs (mifepristone 16 percent; misoprostol 23 percent).

\section{Only seven percent of informal providers are} familiar with post-coital contraception. Among the 35 informal providers aware of emergency contraception, 60 percent provide it and 31 percent have had a client ask about this method of contraception in the three months preceding the study (Table 5.9).

\section{Familiarity with and attitudes about abortion legislation}
Less than one-third (29 percent) of all informal providers interviewed know that abortion is legal in India (data not shown). Of the 140 informal providers who know abortion is legal, most know that a woman can obtain an abortion legally if her health is endangered (94 percent) or in the event of foetal malformation (92 percent), contraceptive failure (86 percent) or rape (87 percent) (Table 5.10). Fewer (65 percent) informal providers aware of the legality of abortion know that

Table 5.8

Awareness and prescription of medical abortion (\%)

Heard of medical abortion

Heard of mifepristone, Mifegest or Mifeprin

Heard of misoprostol, Cytotec, Cytolog or Zitotec (\%)

Informal providers (n)

Know whether mifepristone, Mifegest or Mifeprin are available locally

Know whether misoprostol, Cytotec, Cytolog or Zitotec are available locally

Used mifepristone, Mifegest or Mifeprin

Used misoprostol, Cytotec, Cytolog or Zitotec

Informal providers familiar with medical abortion (n)
12.7

6.1

5.5

489

41.9

38.7

16.1

22.6

62 
unmarried women can obtain abortions legally (65 percent). Almost all of informal providers (93 percent) believe incorrectly that spousal consent is required for a woman to obtain an abortion (data not shown).

\section{Table 5.9}

Awareness and prescription of emergency contraception (\%)

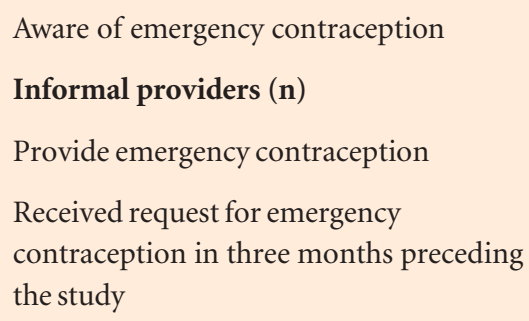

Informal providers familiar with emergency contraception (n)

Informal providers described the circumstances under which they personally support abortion (Table 5.11). Although a majority do not know abortion is legal in India, many feel that a woman should be able to have an abortion in a variety of circumstances. Most informal providers endorse abortion if a woman's health is endangered (92 percent), in the event of foetal malformation (91 percent), if the woman is unmarried (88 percent), or if the pregnancy is a result of rape (88 percent). Slightly fewer respondents support abortion if the woman cannot afford the child (75 percent) or the woman does not want another child (71 percent), and very few if the foetus is female (5 percent) or male ( 3 percent).
Table 5.10

\section{Circumstances under which providers believe abortion is legal (\%) a}

\begin{tabular}{|l|l|}
\hline Unmarried woman & 65.0 \\
\hline Contraceptive failure & 85.7 \\
\hline Pregnancy resulting from rape & 87.1 \\
\hline Woman's health endangered by pregnancy & 94.3 \\
\hline Chance of foetal malformation & 92.1 \\
\hline Aware that abortion is legal (n) & $\mathbf{1 4 0}$ \\
\hline
\end{tabular}

${ }^{a}$ May total to more than 100 percent because of multiple responses.

\section{Table 5.11}

Circumstances under which providers endorse abortion (\%) ${ }^{\text {a }}$

\begin{tabular}{l|c}
\hline Woman does not want another child & 70.8 \\
\hline Woman cannot afford child & 74.6 \\
\hline Unmarried woman & 88.3 \\
\hline Contraceptive failure & 78.3 \\
\hline Rape & 87.7 \\
\hline Woman's health endangered by pregnancy & 92.4 \\
\hline Foetal malformation & 91.0 \\
\hline Female foetus & 4.7 \\
\hline Male foetus & 2.7 \\
\hline Informal providers (n) & $\mathbf{4 8 9}$ \\
\hline May total to more than 100 percent because of multiple responses.
\end{tabular}




\section{Summary of Findings and Conclusion}

We conducted a situation analysis of formal and informal abortion services in six purposively selected districts of Rajasthan. While the sample is largely urban, drawn from district headquarters and six pre-specified towns, we also gathered data from villages and smaller towns surrounding those urban localities. As we interviewed administrators, providers and conducted physical and equipment assessments at 105 certified and uncertified abortion facilities in the formal sector, and interviewed 489 abortion providers in the informal sector, the study offers important insights into the availability and organisation of abortion services in the sampled areas in Rajasthan.

\section{Access}

- Despite a strong national commitment to improve the accessibility of abortion services in India, only one-third ( 35 percent) of the formal-sector facilities we sampled are in the public sector and 28 percent are in rural areas. Among all of the primary health centres and community health centres identified in the catchment area, only 21 and 65 percent, respectively, offer abortion services. Poor rural women thus remain with few options when faced with unwanted pregnancy.

- Almost two-thirds (65 percent) of private-sector facilities and 58 percent of public-sector facilities sampled are not certified to provide abortions under the MTP Act. While the recent decentralisation of the facility certification process to the district level (Government of India 2002) is likely to increase the number of certified facilities, other issues may need to be addressed or clarified in order to encourage uncertified facilities to comply with legislative requirements. For example, facilities that provide only non-allopathic abortion services remain largely uncertified because they do not believe that certification is required by law.

- While the majority of facilities are not certified to provide abortions, 63 percent of the formal-sector abortion providers we interviewed have the requisite education and/or training to perform abortions, with very little difference across health sectors. This suggests that services in the formal sector, whether legal or not, are likely to be safe. Increasing opportunities for training in abortion will further enlarge the pool of certified abortion providers, a critical step in improving access to legal abortion. Future policy discussions, however, should consider the feasibility of alternative mechanisms for uncertified providers, including those trained in Indian systems of medicine, to obtain and demonstrate technical competence in abortion.

\section{Quality of care}

- The quality of abortion services in the formal sector can be improved substantially. While surgical abortion services are provided in both the private and public sectors, private-sector facilities are better prepared to provide high-quality invasive abortion services, generally having cleaner facilities and more essential equipment onsite. 
- The majority of formal-sector abortion providers, particularly in public and uncertified facilities, use outdated techniques to perform surgical abortions, such as dilatation and curettage (early first trimester 52 percent; late first trimester 64 percent; second trimester 53 percent). The easier and safer techniques of electric and manual vacuum aspiration are used less frequently, even for abortions at the earliest gestational ages. While almost all providers have training in dilatation and curettage (77 percent), fewer are trained in aspiration abortion techniques (manual 58 percent; electric 61 percent). Incorporation of modules on electric and manual vacuum aspiration in professional programmes for gynaecologists and non-gynaecologists alike and in abortion-training centres is critical to decreasing the complications associated with dilatation and curettage. In-service training in these methods is also important for providers who have already completed their training in gynaecology and/or abortion.

- Pain management for surgical procedures must be improved. Nearly one-quarter (23 percent) of providers use general anaesthesia for abortions at gestations of 8 weeks or less and 30 percent use it for abortions between 9 and 12 weeks' gestation, despite the risks associated with such anaesthesia. Conversely, a fair number of providers report using no method of pain management in first-trimester abortions (early first trimester 23 percent; late first trimester 4 percent). Increased use of analgesics, conscious sedation or local anaesthesia with para-cervical block for all first-trimester abortions may improve client acceptability and, when compared to general anaesthesia, can reduce the length and cost of hospital stays.

- While a surprising 57 percent of formal providers report being familiar with medical abortion, further efforts should be made to increase knowledge of non-invasive abortifacients holds great promise. According to a 2002 amendment of the MTP Rules, mifepristone-misoprostol medical abortion can be provided by certified providers at uncertified facilities as long as they establish and document a relationship with a certified facility for back up (Government of India 2002). Adoption of medical abortion in the government norms, however, is critical to ensuring access to this safe and effective abortion method in the public sector.

\section{Barriers to care}

- While nearly all facilities in the formal sector are easily accessible by road or public transportation, significant financial barriers to care exist. The cost of abortions in the formal sector ranges widely, but, on average, is upwards of 318, 497 and 750 Indian Rupees, respectively, for those performed in the early first trimester, late first trimester and second trimester. Certified private facilities charge the most for first-trimester services suggesting again that poor women remain at an important disadvantage when attempting to access legal services.

- Facilities routinely refuse to perform abortions in a number of circumstances, including if the women presents alone (72 percent), is married but nulliparous (53 percent) or is unmarried (37 percent), thus severely compromising women's reproductive rights. 
- Unnecessary consent of women's husbands and other family members is obtained in most of the facilities we sampled. While the MTP Act stipulates that only a woman's (or that of her guardian in the case of a minor or mentally disabled woman) consent is required, 71 percent of facilities report taking her husband's consent before providing an abortion.

- Formal-sector providers are well aware of the majority of circumstances under which abortion is legal in India. Confusion remains, however, regarding the legality of abortion among unmarried women, as 30 percent of providers believe abortions among such women are illegal. Similarly, 55 percent of providers believe incorrectly that husband's consent pre-abortion is mandated by law.

\section{Post-abortion care}

- Appropriate post-abortion care requires additional attention. Despite the removal of contraceptive targets from the Family Welfare Programme, 42 percent of providers insist on the adoption of a contraceptive method post abortion with even a greater proportion (53 percent) doing so in the public sector. Among these providers, a strong emphasis remains on permanent or long-term methods such as sterilisation and intrauterine devices. While post-abortion contraception should be discussed with all abortion clients and encouraged when appropriate, the importance of voluntary adoption needs to be underscored and temporary methods emphasised further, as in some cases, they may best meet women's needs.

- While the majority ( 89 percent) of providers report advising women to return immediately in the event of excessive bleeding following an abortion, far fewer recommend that women seek care in the case of severe abdominal pain or distension (49 percent) or when signs of infection, such as fever (36 percent) or foul-smelling discharge (20 percent), occur. Provider training progammes should highlight the potential for and signs of post-abortion complications to further increase provider's vigilance for such complications.

\section{Informal providers}

- A vast array of informal providers offers women services for delayed menstruation or unwanted pregnancy. Informal providers may appear particularly accessible to women because they are far more prevalent in rural areas than formal providers, are generally well known in the community in which they practise, maintain extended working hours, and sometimes provide care at women's homes. Increasing access to affordable, high-quality formal providers more generally, and particularly in rural areas, may decrease community reliance on informal providers.

- The majority ( 75 percent) of informal providers report providing women with tablets to provoke abortions. As most of these providers remain unfamiliar with registered 
non-invasive abortifacients, such as

mifepristone and misoprostol, however, not surprisingly, they report low success rates (41 percent). With increasing access to mifepristone and misoprostol across the country, exploring the feasibility of safe and effective provision of medical abortion by some informal providers, such as nurses, may prove important.

- Few informal providers report using invasive methods for the treatment of delayed menstruation. When they do, however, they indicate charging rates comparable to those of first-trimester abortions in the formal sector. Further research at the community level is needed to examine why invasive abortion treatments are sought from informal providers when they are available in the formal sector for approximately the same cost.

- Only 29 percent of all informal providers know that abortion is legal in India. Increasing knowledge of the legality of abortion among such providers is important, as it is likely to encourage their referral when complications arise.

\section{Conclusion}

The most significant policy message emerging from this study is that access to affordable, high quality, legal abortion services must be improved, particularly in rural areas. Until this is done, informal providers and uncertified facilities will remain the best option for poor and rural women despite the fact that abortion has been legal in India for over 30 years. Recent amendments in the MTP Act and Rules make this message particularly timely. The decentralisation of facility certification to the district level is an important step in increasing access to legal abortion services. Similarly, the provision of mifepristonemisoprostol by certified providers at uncertified facilities which have an established link to certified facilities for back-up services may increase the number of legal abortion providers. Further efforts, however, are critical to increasing the number and quality of public-sector facilities providing abortion. Discussions regarding the best way to do this should capitalise on the momentum from the adoption of the amendments described above and bring together policy-makers, providers, women's health advocates and researchers. 


\section{References}

Census of India.2002.2001 Census Results. http://www.censusindia.net/results/2001census_data_index.html. Accessed on August 18, 2004.

Chhabra R and Nuna SC. 1994. Abortion in India: An Overview. New Delhi, India: Veerendra Printers.

Duggal R and Barge S. 2003. Synthesis of Multi-centric Facility Survey: A Summary. Working draft prepared for Abortion Assessment Project India (AAP)-I dissemination workshop. New Delhi, India.

Elul B, Barge S, Verma S et al. 2004a. Unwanted Pregnancy and Induced Abortion: Data from Men and Women in Rajasthan India. New Delhi, India: Population Council.

Elul B, Bracken H, Verma S et al. 2004b. Unwanted Pregnancy and Induced Abortion in Rajasthan, India: A Qualitative Exploration. New Delhi, India: Population Council.

Ganatra BR. 2000. Abortion research in India-what we know, what we need to know, in Women's Reproductive Health in India, ed. S Jejeebhoy and R Ramasubban. New Delhi, India: Rawat Publications.

Government of India. 1971. The Medical Termination of Pregnancy Act. Act No. 34.

Government of India. 2002. The Medical Termination of Pregnancy (Amendment) Act.

Hirve S. 2003. Abortion Policy in India: What Is and What Needs to Be...Present and Future Challenges. Mumbai, India: Centre for Enquiry into Health and Allied Themes (CEHAT) and Research Centre for Anusandhan Trust.

Johnston HB. 2002. Abortion Practice in India: A Review of the Literature. Mumbai, India: Centre for Enquiry into Health and Allied Themes (CEHAT) and Research Centre for Anusandhan Trust.

Khan ME, Barge S, Kumar N et al. 1999. Abortion in India: Current situation and future challenges, in Implementing a Reproductive Health Agenda in India: The Beginning, ed. S Pachauri. New Delhi, India: Population Council.

Ministry of Health and Family Welfare (MOHFW). 1998. District Household Survey (Phase I). http://mohfw.nic.in/breakfile2.html. Accessed on May 10, 2004.

Ministry of Health and Family Welfare (MOHFW). 1999. District Household Survey (Phase II). http://mohfw.nic.in/break2file2.html. Accessed on May 10, 2004. 


\section{Authors}

Sandhya Barge is associate director, Centre for Operations Research and Training, Vadodara, India.

Hillary Bracken is a staff programme associate, International Programs Division, Population Council, New York, NY, USA.

Batya Elul is a programme associate, International Programs Division, Population Council, New York, NY, USA. Nayan Kumar is a field manager, Centre for Operations Research and Training, Vadodara, India.

Wajahat U. Khan is a research executive, Centre for Operations Research and Training, Vadodara, India.

Shalini Verma was a research officer, Population Council, New Delhi, India, and is now a senior research manager at TNS India, New Delhi, India.

Carol Camlin is a public health consultant in Ann Arbor, MI, USA. 
QP Population Council

South \& East Asia—Regional office

Zone 5-A Ground Floor

India Habitat Centre

Lodi Road

New Delhi 110 003, India

\section{cort}

Centre for Operations Research and

Training

402 Woodland Apartments

Race Course Circle

Vadodara 390 007, India 